Illinois State University

ISU ReD: Research and eData

Theses and Dissertations

$2-14-2018$

\title{
Voices Of Cooperating Teachers: Comparing Experiences Of Professional Development School And Traditional Student Teaching Models
}

Katherine Hlavach Bruemmer

Illinois State University, kbruemmer@comcast.net

Follow this and additional works at: https://ir.library.illinoisstate.edu/etd

Part of the Teacher Education and Professional Development Commons

\section{Recommended Citation}

Bruemmer, Katherine Hlavach, "Voices Of Cooperating Teachers: Comparing Experiences Of Professional Development School And Traditional Student Teaching Models" (2018). Theses and Dissertations. 824. https://ir.library.illinoisstate.edu/etd/824

This Dissertation is brought to you for free and open access by ISU ReD: Research and eData. It has been accepted for inclusion in Theses and Dissertations by an authorized administrator of ISU ReD: Research and eData. For more information, please contact ISUReD@ilstu.edu. 


\title{
VOICES OF COOPERATING TEACHERS: COMPARING EXPERIENCES OF \\ PROFESSIONAL DEVELOPMENT SCHOOL AND TRADITIONAL \\ STUDENT TEACHING MODELS
}

\author{
Katherine Hlavach Bruemmer
}

106 Pages

This mixed-methods sequential study compared the experiences of cooperating teachers (CT) in a Professional Development School program and a traditional student teaching program. Cooperating teachers' perspectives were gathered through an on-line survey and interviews. Information gathered was related to the preparation for acting as a $\mathrm{CT}$, involvement with the student teaching process, professional benefits of acting as a $\mathrm{CT}$, impact of the experience on their own teaching, and suggestions for improvements to the teacher preparation programs. Results indicate that no significant differences were found between the experiences of CTs in the different programs. Findings did reveal that CTs desire greater participation in the process and offer suggestions for improvement related to preparation program requirements such as length of student teaching, curricular knowledge, and edTPA.

KEYWORDS: cooperating teacher, student teacher, Professional Development School, traditional student teaching program, edTPA, university supervisor 
VOICES OF COOPERATING TEACHERS: COMPARING EXPERIENCES OF

PROFESSIONAL DEVELOPMENT SCHOOL AND TRADITIONAL

STUDENT TEACHING MODELS

KATHERINE HLAVACH BRUEMMER

A Dissertation Submitted in Partial

Fulfillment of the Requirements

for the Degree of

DOCTOR OF EDUCATION

School of Teaching and Learning

ILLINOIS STATE UNIVERSITY 
(C) 2018 Katherine Hlavach Bruemmer 
VOICES OF COOPERATING TEACHERS: COMPARING EXPERIENCES OF

PROFESSIONAL DEVELOPMENT SCHOOL AND TRADITIONAL STUDENT TEACHING MODELS

KATHERINE HLAVACH BRUEMMER

COMMITTEE MEMBERS:

Nancy Latham, Chair

Lydia Kyei-Blankson

Thomas Crumpler 


\section{ACKNOWLEDGMENTS}

I would like to thank the members of the committee who supported this journey. To Dr, Latham, thank you for answering all my questions and taking on a doc student who had actually never been your student. I am thankful that you shared your professional expertise and guidance with me. To Dr. Crumpler, thank you for continually sending me to the library. I mean that in the best way possible. Your suggestions always sent me on a quest for greater insight. I am thankful that you are the bookends of my dissertation journey. It is hard to imagine that my first doc class was with you, and now we have reached the final chapter. To Dr. Kyei-Blankson thank you for your patience. As a student who has always been much more comfortable in the world of narrative, your specific and thoughtful suggestions helped me understand the depth of quantitative knowledge and the story that numbers have to tell.

This journey has taken me at times, both far away from the comforts and responsibilities of my family, and closer to the deepest parts of who I am as a daughter, mother, and wife. In the moments when I could I not be present to my children and husband, others held them, laughed with them, and shared life with them. In the dreams that reminded me that my dad, who left this life while I attended class, bestowed on me the duty to be an excellent educator, I found courage and purpose to continue. In the encouraging phone calls from my mom, a woman whose own educational journey began in a one-room schoolhouse and ended in nursing school, I learned persistence and felt truly inspired. In the daily tasks done while I wrote and researched and fretted, I noticed the love of a kind soul. I noticed all the bedtime stories read, dishes cleaned, groceries gathered, beds made, computer glitches fixed, and love notes written. I noticed. And I couldn't have completed this without you, Kevin.

K. H. B. 


\section{CONTENTS}

Page

ACKNOWLEDGMENTS

$\begin{array}{ll}\text { CONTENTS } & \text { ii }\end{array}$

TABLES Di v vi

CHAPTER I: INTRODUCTION 1

Statement of the Problem 3

$\begin{array}{ll}\text { Purpose of the Study } & 4\end{array}$

$\begin{array}{ll}\text { Research Questions } & 4\end{array}$

Significance of the Study $\quad 5$

$\begin{array}{ll}\text { Definition of Terms } & 6\end{array}$

$\begin{array}{ll}\text { Professional Development Schools (PDS) } & 6\end{array}$

$\begin{array}{ll}\text { Traditional Student Teaching Model } & 7\end{array}$

$\begin{array}{ll}\text { Student Teachers (ST) } & 7\end{array}$

$\begin{array}{ll}\text { Cooperating Teacher (CT) } & 8\end{array}$

$\begin{array}{ll}\text { University Supervisor (US) } & 8\end{array}$

Delimitations and Limitations of the Study $\quad 8$

$\begin{array}{ll}\text { Organization of the Study } & 8\end{array}$

CHAPTER II: LITERATURE REVIEW 10

Cooperating Teachers: A Brief History 10

Professional Development Schools 11

$\begin{array}{ll}\text { Goals of PDS } & 13\end{array}$

$\begin{array}{ll}\text { Traditional Teacher Preparation } & 15\end{array}$ 
Selection and Preparation of Cooperating Teachers

Selection of Cooperating Teachers

Preparation of Cooperating Teachers

Impact of Working as a CT

Impact on CTs in PDS

Impact on CTs in non-PDS

Changing Roles of CTs

Analysis and Considerations

CHAPTER III: METHODS

Overview

Research Questions

Theoretical Foundation

Research Design and Rationale

Procedures

Participants and Research Setting

Ethical Considerations

Instrumentation

Data Collection Procedures $\quad 35$

Data Analysis $\quad 36$

$\begin{array}{ll}\text { Reliability and Validity } & 37\end{array}$

$\begin{array}{ll}\text { Researcher Positionality } & 38\end{array}$

CHAPTER IV: FINDINGS

Phase 1: Demographics $\quad 39$ 
Phase 1: Research Question One $\quad 42$

$\begin{array}{ll}\text { PDS Response } & 42\end{array}$

Traditional Response $\quad 43$

Comparing PDS and Traditional Programs 44

Phase 1: Research Question Two 45

PDS Response $\quad 46$

Traditional Response $\quad 46$

Comparing PDS and Traditional Programs 47

CT Suggestions for Greater Involvement 49

PDS response $\quad 49$

$\begin{array}{ll}\text { Traditional response } & 50\end{array}$

Phase 1: Research Question Three $\quad 52$

PDS Response $\quad 53$

Traditional Response $\quad 55$

Phase 1: Research Question Four $\quad 57$

$\begin{array}{ll}\text { PDS Response } & 57\end{array}$

$\begin{array}{ll}\text { Traditional Response } & 58\end{array}$

Phase 1: Research Question Five $\quad 60$

$\begin{array}{ll}\text { PDS Response } & 60\end{array}$

$\begin{array}{ll}\text { Traditional Response } & 63\end{array}$

$\begin{array}{ll}\text { Phase 2: Interviews with Cooperating Teachers } & 67\end{array}$

Biographical Information of the Interviewees $\quad 69$

$\begin{array}{ll}\text { Preparation for Acting as a CT } & 71\end{array}$ 
Involvement of the CT with Student Teaching Process 72

$\begin{array}{ll}\text { Professional Benefits } & 74\end{array}$

$\begin{array}{ll}\text { Impact on CT Teaching } & 75\end{array}$

Improvements for the Student Teaching Process 76

$\begin{array}{ll}\text { edTPA as a Complication } & 77\end{array}$

$\begin{array}{ll}\text { Preparation of ST } & 78\end{array}$

Differences between PDS and Traditional Programs 79

CHAPTER V: CONCLUSIONS, IMPLICATIONS, AND RECOMMENDATIONS 81

$\begin{array}{ll}\text { Introduction } & 81\end{array}$

Summary of the Study $\quad 81$

$\begin{array}{ll}\text { Summary of Findings } & 82\end{array}$

$\begin{array}{ll}\text { Discussion and Implications } & 86\end{array}$

$\begin{array}{ll}\text { PDS Goals of Shared Responsibilities } & 87\end{array}$

Relationship with University Supervisor $\quad 88$

Structure for Completion of edTPA $\quad 88$

CT Desire to Be More Involved $\quad 89$

$\begin{array}{ll}\text { Limitations } & 89\end{array}$

$\begin{array}{ll}\text { Recommendations for Future Studies } & 90\end{array}$

$\begin{array}{ll}\text { REFERENCES } & 91\end{array}$

APPENDIX A: COOPERATING TEACHER SURVEY 102

APPENDIX B: RECRUITMENT LETTER 106 


\section{TABLES}

Table Page

1. Cooperating Teacher Demographic Information 40

2. Value of Pre-Student Teaching Information: CTs with PDS STs 43

3. Value of Pre-Student Teaching Information: CTs with Traditional STs 44

4. Involvement for CTs with STs in PDS and Traditional Programs 47

5. CT Desire to Have Input on Student Teaching Field Experience 48

6. CTs with STs in PDS Programs Desire for More Involvement 49

7. CTs with STs in Traditional Programs Desire for More Involvement 51

8. CTs with STs in PDS Programs Suggestions for Improvement 61

9. CTs with STs in Traditional Programs Suggestions for Improvement 64

10. Cooperating Teachers Interviewed 71 


\section{CHAPTER I: INTRODUCTION}

Current teacher preparation in the United States includes both university classroom-based pedagogical preparation and clinical K-12 classroom experience which intends to provide theoretical support for practical application of teaching methods. This two-pronged approach evolved through a variety of teacher education methods developed in individual normal schools and state-run programs dating from the late 1800s (Grant \& Murray,1999; Pushkin, 2001; Tozer, Violas, \& Sense, 1993). As demand grew for classroom teachers, so too did the need for teacher preparation programs. These programs were established across the country with local norms and expectations. This localized programming created a wide variety of requirements for future teachers across the country. Eventually, national attention was brought to the idea of a standardized or common teacher preparation system, and thus organizations such as the National Council for Accreditation of Teacher Education (NCATE) were established to evaluate and provide guidelines and accreditation to teacher preparation programs. (Darling-Hammond \& Bransford, 2005; Levine, 2006).

Although national standards exist for teacher preparation, a great deal of variety persists among programs causing concern and debate related to the most effective methods of preparing future teachers. Concern for the quality of all teacher preparation programs has prompted national research and reform movements through colleges of education, private providers, and government agencies. Many of the reform efforts suggest that a greater emphasis on clinical experience will ensure that future teachers are well-prepared to enter classrooms (Dennis, 2016; Fraser \& Watson, 2014; Washut, Heck \& Bacharach, 2015). Programs such as laboratory schools, centers of pedagogy, professional development schools, and partnership models have 
been instituted to enhance clinical experiences. These programs involve the collaboration of universities, local school districts, and classroom teachers.

Teacher preparation programs are researched for effectiveness in terms of supporting future classroom teachers and their students (Burton \& Greher, 2007; Ridley, Hurwitz, Hackett, \& Miller, 2005; Theiss, \& Grigsby, 2010). Studies indicate that a variety of factors support the ST throughout the preparation program. A key to a positive experience for the ST is working with a well-qualified CT. This partnership, along with the support of the university faculty and local school districts, helps to establish an excellent set of skills and knowledge for the ST (Allen, Perl, Goodson, Sprouse, 2014; Vernon-Dotson \& Floyd, 2012)

Extended time spent in the classroom of an experienced teacher provides a key component in the preparation of future teachers who are often encouraged to apply universitybased experiences to practical classroom experiences during clinical placements (DarlingHammond \& Bransford, 2005). The mentoring also shifts from university personnel to the classroom cooperating teacher. As Clarke (2001) explains cooperating teachers (CT) provide significant influence on the development of novice teachers. Several studies indicate that the CT is the most significant influence on a student teacher (ST) (Griffin et al., 1983; Karmos \& Jacko, 1977; McIntyre \& Byrd, 1998). Given their substantial role in the development of future teachers, CTs' interactions with STs have been studied extensively (Allen, Howells \& Radford, 2013; Breault, 2014; Castle, Fox, \& Souder, 2006 Cuddapah, Masci, Smallwood \& Holland, 2008). These interactions with CTs significantly impact the student teaching experience for the student teacher (Allen, Perl, Goodson, Sprouse, 2014; Vernon-Dotson \& Floyd, 2012). More research needs to be done to examine the experience of the $\mathrm{CT}$ and the potential impact of the experience on the CTs' teaching practices (Baum, Powers-Costello, VanScoy, Miller, \& James, 
2011; Dooley, Dangel, \& Farran, 2011; Hoffman, Wetzel, Maloch, Greeter, Taylor, DeJulio, \& Vlach, 2015; Paulson \& Latham, 2015). Further research also needs to examine the practitioner expertise held by the $\mathrm{CT}$ as a potential source of knowledge to inform the teacher preparation process. Specifically, it is important to understand the experience of CTs as they engage with the student teaching process. Additionally, to promote professional advancement for CTs, research needs to examine the effects of hosting a ST on the CTs' attitudes, teaching strategies, and participation in the organization and implementation of the student teaching process. This knowledge can inform the university community and future CTs. This research can be enhanced further through examining the differences between two different student teaching models: traditional and Professional Development School teacher preparation models.

\section{Statement of the Problem}

Despite their significant role and impact on the student teaching process, the experience of and impact on CTs has not been thoroughly investigated. Some studies indicated that CTs experience positive professional outcomes as a result of working in the Professional Development School model (Chase \& Merryfield, 1998; Clinard, 1995; Clinard \& Ariav, 1997; Sandholtz \& Wasserman, 2001). Additionally, studies indicate that CTs benefit from increased communication with other education professionals, development of new teaching ideas, and increased time for their own curriculum development (Landt, 2004; Shroyer et al., 2007). CTs in traditional student teaching models also experienced professional benefits as a result of engaging with the student teaching process (Arnold, 2002; Ganser, 1996; Ganser \& Wham, 1998; Weasmer \& Woods, 2003).

Additional research is needed to understand the perceptions of the experiences of the CT as they interact with university personnel and the ST. Specifically, preparation of the CT and 
input from the $\mathrm{CT}$ are elements of teacher preparation programs that have not received a great deal of attention. An investigation of the impact of student teaching on the CT can shed light on the potential professional benefits to the CT. Given the wide variety of student teaching programs, a comparative study of two programs from the perspective of CTs will provide a more in-depth picture of the programs. The two programs available at the research site for this study are a voluntary Professional Development School model and the standard traditional sixteenweek model. For the purpose of this study, these are the two programs that will be compared. The findings could support and enhance the teacher preparation experience for all members at the research site and other similar teacher preparation locations.

\section{Purpose of the Study}

The purpose of the study was to discover the perspectives of CT in relation to working with students from both traditional and PDS teacher preparation models at the same university. Specific areas of interest were the preparation of the CT for hosting the ST, the level of involvement of the $\mathrm{CT}$ in the STs' preparation, benefits and challenges during the process, and the perceived impact of the student teaching experience on the CT.

Sharing this information with university program coordinators, faculty, as well as student teachers, could encourage positive changes, including encouraging greater CT involvement and professional growth.

\section{Research Questions}

To investigate the above, the study will focus on the following research questions:

1. How were CTs prepared for the student teaching experience? Is the level of preparation different when preparing for STs in the PDS versus traditional model? 
2. How involved are CTs in the teacher preparation process? Is the level of involvement different when working with STs from the PDS versus traditional model?

3. What are the perceptions of professional benefits to the CT? Do the benefits differ when working with STs from the PDS versus traditional model?

4. What are the perspectives of CT related to the impact of the experience on their own teaching strategies? Does this impact differ when working with a ST from a PDS versus traditional model?

5. How might the student teaching process be improved for CTs or STs? Do the suggestions differ when working with STs from a PDS versus traditional model?

\section{Significance of the Study}

Teachers play a key role in the development of students as citizens and workers who "need greater knowledge and skill to survive and succeed" (Darling-Hammond \& Bransford, 2005 , p. 2). Teacher preparation programs play a vital role in the development and preparation of quality educators who are ready to meet the demands of the changing educational and workforce landscape (Darling-Hammond \& Bransford, 2005). Most teacher preparation programs involve student-teaching or clinical placement which provides a time of cooperation between the student teacher and an experienced classroom teacher (CT). According to research, this relationship between the student teacher and cooperating teacher has a significant impact on the student teacher (Griffin et al., 1983; Karmos \& Jacko, 1977; McIntyre \& Byrd, 1998). Given the significant role of CTs in the student teaching process, research to further understand the experience of CTs can improve the teacher preparation process. This study aims to enhance the understanding of the experience for CTs and give voice to their concerns and suggestions for improving the PDS and traditional teacher preparation process. 


\section{Definitions of Terms}

The following terms apply throughout the entire study. The terms are specific to the university which the student teachers attended.

\section{Professional Development School (PDS)}

According to the National Association for Professional Development Schools (Brindley, Field \& Lessen, 2008, p. 2-3), a school-university partnership must possess nine required essentials:

1. A comprehensive mission that is broader in its outreach and scope than the mission of any partner and that furthers the education profession and its responsibility to advance equity within schools and, by potential extension, the broader community;

2. A school-university culture committed to the preparation of future educators that embraces their active engagement in the school community;

3. Ongoing and reciprocal professional development for all participants guided by need;

4. A shared commitment to innovative and reflective practice by all participants;

5. Engagement in and public sharing of the results of deliberate investigations of practice by respective participants;

6. An articulation agreement developed by the respective participants delineating the roles and responsibilities of all involved;

7. A structure that allows all participants a forum for ongoing governance, reflection, and collaboration;

8. Work by college/university faculty and $\mathrm{P}-12$ faculty in formal roles across 
institutional settings; and

9. Dedicated and shared resources and formal rewards and recognition structures.

Within the university to be studied, the PDS program is described as a year-long experience that includes fall clinical experiences, spring student teaching, college classes, and mentoring at the same site. The PDS options at the university include preparation in grade levels from early childhood through secondary education. The sites also vary between rural, suburban and urban environments.

\section{Traditional Student Teaching Model}

According to the university website (K-12 and Secondary Education, 2018), traditional student teaching is a sixteen-week period of time in which the student teacher observes and then take on greater responsibilities in the classroom. For the early childhood, elementary and middle level placements students have the option of one sixteen-week session with in-state or out of state, or an international option with eight weeks in-state and eight weeks in a partner school in Europe.

\section{Student Teachers (ST)}

Student teaching is the capstone of the teacher education process and occurs after clinical experiences and all major course requirements have been met. During student teaching, students steadily increase classroom responsibilities and demonstrate competency in planning, assessment, instruction, and other professional tasks with the guidance of an experienced mentor (Darling-Hammond \& Bransford, 2008). 


\section{Cooperating Teacher (CT)}

Cooperating teachers in a PDS or traditional model hold a collaborative position with university supervisors in terms of supporting the student teacher. Cooperating teachers offer their classroom space, collaborative input and professional experience to the intern. The CT also works closely with the university supervisor to provide feedback to the ST in regards to multiple observations and evaluations.

\section{University supervisor (US)}

This individual is an employee of the university that maintains coordinates and facilitates the student teaching experience. They serve as liaisons between the university and host schools.

\section{Delimitations and Limitations of the Study}

Participation in the study was limited to CTs who are associated with one mid-sized institution in central Illinois. The schools in which the CTs teach are limited to the partner schools of the university. These schools are urban, suburban, and rural in size. The STs involved with the CTs were students at the same institution which limits the capacity to generalize the data found in the study.

\section{Organization of the Study}

Chapter One introduces the study and provides an overview of student teaching and the significant role that cooperating teachers play in the preparation of new teachers. Chapter One also includes a statement of the problem, purpose of the study, research questions, significance of the study, definition of terms and delimitations and limitations of the study. Chapter Two offers a review of the literature that traces the history of cooperating teachers, a description of both Professional Development Schools and traditional student teaching, an overview of the selection and preparation of cooperating teachers, the impact of working as a cooperating teacher 
in each type of student teaching model, the changing roles of cooperating teachers, and a brief analysis. Chapter Three describes the mixed-methods research design to be used in this study, and Chapter Four details the results of the study. Chapter Five provides the study's summary, implications, and recommendations. 


\section{CHAPTER II: LITERATURE REVIEW}

\section{Cooperating Teachers: A Brief History}

As a means to situate the current experience of cooperating teachers, a brief historical perspective will be provided to highlight the involvement of classroom teachers in the preparation of new teachers. The term cooperating teacher, itself, derived from the practical need of colleges of education to have school teachers cooperate with them to help prepare future teachers (Clarke, Triggs, \& Neilsen, 2014). Normal schools developed as the training grounds for future teachers beginning in the mid-19 ${ }^{\text {th }}$ century (Cornbleth $\&$ Ellsworth, 1994). These schools served to supervise the development of future teachers and became a model for laboratory schools. Teacher involvement in the preparation of new teachers continued in varying degrees until the 1940s and 1950s when the need for clinical educators grew in demand given the changes in both general population and the number of teachers needed (Cornbleth \& Ellsworth, 1994). The increased demand for cooperating teachers prompted cooperation between universities and schools in a variety of models.

By the 1980s a wave of reform prompted an examination of the preparation of future teachers. A Nation at Risk, published in 1983, encouraged educational reform for K-12 schools and colleges of education. Suggestions included adjusting and increasing high school graduation requirements, including a stronger focus on mathematics and science, promoting the field of education to highly qualified candidates, and involving experienced teachers in the training of new teachers. In response to the recommendations, several groups formed to address the educational goals. One such group, The Holmes Group, named for Henry Holmes the graduate education dean of Harvard University in the 1920s who "argued eloquently but to no avail, that universities should strengthen their commitment to teacher education," (Wiggins, 1986, p. 56) 
encouraged improvements in teacher preparation. Specifically, the Holmes Group which was comprised of the deans of colleges of education across the country, advocated for groups of professional educators working together to improve teaching and learning. This process of improvement involved partnership and communication at all levels: universities were encouraged to review teacher training, teacher education courses, and research initiatives for those faculty members directly involved with partnerships; K-12 schools, specifically principals, were encouraged to consider themselves important partners in the training of new teachers; classroom teachers themselves were encouraged to gain the capacity to reflect and collaborate in the preparation of training new teachers (Bradley, 1995; Holmes Group, 1995; Murray 1986). According to Sam Wiggins' 1986 description of the suggested reforms, The Holmes Group institutions proposed a detailed three-tiered approach to the elevation of teachers within the profession, starting with:

the teacher novice as Instructor... [then] the Professional Teacher, who requires a master's degree in teaching and must pass written examinations in academic and pedagogical areas... and the Career Professional license would typically require 'successful doctoral study and demonstration of practical competence.' (p. 57) This elevation of the profession encouraged an almost complete overhaul of the teacher preparation system. This overhaul encouraged adjustments in traditional teacher preparation programs and the development of new programs such as Professional Development Schools (Bradley, 1995).

\section{Professional Development Schools}

Professional Development Schools evolved as a means to enhance the preparation of future teachers. The model involves a collaborative effort among student interns, classroom 
teachers, school districts, and university teacher preparation programs. Successful examples of implementation were examined to determine the potential benefits and challenges for all members, with special attention to the cooperating teachers. As noted by Teitel, 2004, PDS programs have become "a key aspect" of improvement for school districts and universities. Additionally, PDS programs have developed as organized systems with a greater connection between PDS program components and "desired outcomes for students, pre-service teachers and experienced educators." (Teitel, 2004, 402). PDS programs support future teachers and those experienced educators who work with them. The process is viewed as a collaborative and reciprocal effort.

Effective clinical experiences require partnerships between the preparation program (most often a university setting) and community K-12 schools. Research of university-K12 PDS partnerships reveals benefits for all players in terms of professional growth and application of significant theory to classroom settings (Baker, 2011; Cucchiara, 2010; Rosner \& Cooper, 1982). The Professional Development School (PDS), has developed as a comprehensive and widespread partnership model with positive outcomes for students and teachers (Burton \& Greher, 2007;

Damore \& Kapustka, 2011; Libler, 2010).

As the PDS model evolved, policy issues needed to be addressed (Darling-Hammond, 1994). Early in the implementation of PDS models, it was noted that for success to be possible, major changes would need to take place as described by Linda Darling-Hammond and Milbrey McLaughlin:

Despite the prestigious support for PDSs, significant policy supports and changes will be required if PDSs are to take root. States must acknowledge that PDSs are part of the infrastructure of a strong education system, and funding for PDSs must 
be provided through basic aid allocations, just as teaching hospitals receive formula adjustments to acknowledge the special mission they perform. (1995, p. 83)

As highlighted, financial and organizational concerns existed from the formation of the PDS model. If teacher preparation was to change radically so too must the systems that prepare and license teachers. To support the financial needs of the burgeoning programs, grant programs and partnerships with organizations such as the NEA supported local PDS endeavors (Shroyer, Yahnke, Dunn \& Bridges, 2014). However, such financial support was often temporary or specific to a particular university or school district. Systematic changes in organization continue to evolve through isolated pockets of teachers given the state and local priorities and capacities. Changes have been noted in the relationships between local districts and universities, increasing the partnership approach with a shared vision for the development of future teachers. Principals and cooperating teachers are taking more active roles in the process of teacher education. The effectiveness of PDS models and the evaluation of the particular structures continues to be a subject of research (Cuddapah, Masci, Smallwood \& Holland, 2008; Damore, Kapustka \& McDevitt, 2011; Polizzi, 2009; Sandholtz \& Dadlez, 2000; Shroyer, Yahnke, Dunn \& Bridges, 2014) with initial results showing positive outcomes for those involved as well as continued challenges in partnership development.

\section{Goals of PDS}

According to the National Association for Professional Development Schools, nine essentials are required of a PDS (Brindley, Field, \& Lessen, 2008, p. 2-3): 
1. A comprehensive mission that is broader in its outreach and scope than the mission of any partner and that furthers the education profession and its responsibility to advance equity within schools and, by potential extension, the broader community;

2. A school-university culture committed to the preparation of future educators that embraces their active engagement in the school community;

3. Ongoing and reciprocal professional development for all participants guided by need;

4. A shared commitment to innovative and reflective practice by all participants;

5. Engagement in and public sharing of the results of deliberate investigations of practice by respective participants;

6. An articulation agreement developed by the respective participants delineating the roles and responsibilities of all involved;

7. A structure that allows all participants a forum for ongoing governance, reflection, and collaboration;

8. Work by college/university faculty and $\mathrm{P}-12$ faculty in formal roles across institutional settings; and

9. Dedicated and shared resources and formal rewards and recognition structures.

These nine essentials are implemented in a variety of forms given the nature of each partnership. Frequently, the partnerships involve greater contact between interns and classrooms, enhance the professional development of experienced teachers, and encourage research related to educational practice. As envisioned by the goals, clinical experience involves a longer duration and a more intense focus upon collaboration and reflection for the intern, university faculty, and cooperating teacher. Successful partnerships as part of a PDS program have been noted at Kansas State University, Indiana State University, George Mason University, The University of 
South Carolina (Field et al., 2010; Libler, 2010; Parsons, et al., 2016; Shroyer, Yahnke, Dunn \& Bridges, 2014; Vontz, Franke, Burenheide, \& Bietu, 2007). All programs note long-standing relationships between the university and the schools as a key factor in success. Partnerships are essential to the success of the PDS model, but building and sustaining those partnerships is challenging work on a variety of levels for individuals and institutions. Challenges involve economic costs to universities, schools and pre-service teachers, negotiations for roles and responsibilities with an emphasis on collaborative, and a potential shift in course requirements for interns.

Professional Development Schools provide growth opportunities for students, future teachers, principals, university instructors and cooperating teachers. Progress is being made and PDSs continue to evolve and impact a growing number of school communities (Teitel, 2004). As part of the network of professionals involved in PDS programs, CTs benefit from working with others in the development of new teachers (Grossman, 1994; Yendol-Silva \& Dana, 2004). PDS programs have gained popularity while many other successful programs follow a more traditional approach for the preparation of student teachers.

\section{Traditional Teacher Preparation}

Traditional teacher preparation programs developed from early teacher models established in state normal schools which were created to prepare teachers for the growing number of students in public schools. The programs often involved some form of practice teaching or "demonstration lessons" under the guidance of an instructor (Grant \& Murray, 1999, p. 78). Specific criteria for the practice lessons varied among schools then, and that variation continues. Traditional student teaching programs require student teachers to spend some amount of time with a cooperating teaching in a classroom. The extent of student teaching lasts, on 
average, ten weeks up to a year-long residency style program (Darling-Hammond \& Bransford, 2005). Not only might the duration of student teaching vary, but also the requirements of the student teacher in relation to the level of participation required for planning, teaching, grading, and involvement in extra-curricular responsibilities. The roles and responsibilities for CTs also vary depending on the program (Darling-Hammond \& Bransford, 2005).

Within colleges of education, teacher preparation programs have developed that incorporate the elements of increased professional development, engagement of school and university personnel, and increased field experience. In the National Commission of Teaching and America's Future (1997), Linda Darling-Hammond describes successful teacher preparation programs that support the academic and professional lives of teachers. The report encouraged an increase in the quality of teacher preparation and teaching in the United States. As Secretary of the Department of Education, Arne Duncan called for efforts to increase the effectiveness of teacher preparation programs through reforms in traditional teacher preparation models (Duncan, 2010). In addition to these, the National Council for the Accreditation of Teacher Education (NCATE, 2010) released a report encouraging increased clinical practice in teacher education.

As a result of the above efforts to encourage improved teacher preparation, several programs evolved within traditional student teaching programs. The call for greater partnership between local school districts and university teacher preparation programs has prompted new initiatives and reforms in existing programs. Over the past twenty-five years, "there has been an explosion of both alternate platforms for preparing teachers and different stakeholders working in teacher education" (Wilson, 2014, p. 183). These programs come in a variety of forms with specific goals and outcomes based on the developers of the programs such as Project CAUSE (Waddell \& Vartuli, 2015) at the University of Missouri created to support the urban community 
near the university and UTeach at the University of Texas-Austin (DeMonte, 2016) focused on promoting teaching in the areas of math and science. In addition to specific initiatives, residency models have been suggested, and programs have been instituted at several universities. These models are based on the medical student training model in which residents "learn to practice medicine by working alongside skilled physicians" (DeMonte, 2016, p. 67). These models, with extended clinical experiences, emphasize the mentoring relationships that needs to be established between CTs and STs. These partnerships encourage all those involved in the teacher preparation program to interact, share ideas and practice pedagogical concepts.

The significance of clinical experience highlights the importance of CTs in the preparation of new teachers. Traditional student teaching models, regardless of format, require CTs who are able to mentor, reflect, supervise, and advice, often without sufficient training to do so (Clarke, Triggs, \& Nielsen, 2014). The role of the classroom teacher in the student teaching process continues to change and "cooperating teachers are expected to play a greater role in the overall training of preservice teachers" (Kahn, 2001). With a growing demand for high quality teacher preparation and clinical experience, the selection and preparation of cooperating teachers holds increased significance for success in preparing future teachers.

\section{Selection and Preparation of Cooperating Teachers}

Given the significance of the role of the CT and the calls for increased clinical experience, the partnership between universities and classroom teachers needs to be well established. Selecting and preparing CTs supports future teachers and the content courses of the universities. 


\section{Selection of Cooperating Teachers}

Research indicates that much of the responsibility for selecting those who will serve as CTs is held by local school administrators (Sawchuk, 2012; Zemek, 2008). These decisions are based upon a variety of factors such as professionalism, ability to collaborate, years of teaching experience, good mentoring skills, and the ability to communicate educational content (Magaya \& Crawley, 2011). This selection method could be problematic if the perception of the administrator and the goals of the university preparation program are not in sync. If the teacher selected by the administrator feels a sense of obligation to accept the responsibility based on employer/employee dynamic, the level of commitment or sincere desire to support the ST may be lacking. To avoid these potential pitfalls, some teacher preparation programs have designed a method of selecting cooperating teachers that involves both administrator recommendations and an interview process that helps to match CTs and STs (Sawchuk, 2012). These are attempts to strengthen the cooperative relationship needed between the CT and ST.

As described in the pilot study for this research project (Bruemmer, 2016) all 19 of the respondents indicated the primary reason for working as a CT was to support the teaching profession. This suggests that many teachers are willing to serve as CTs. Their classroom experience and knowledge are important factors in the preparation of new teachers. The current study will conduct further investigation into the contributions of CTs in the student teaching process.

\section{Preparation of Cooperating Teachers}

Once CTs have been selected, their preparation varies widely among teacher preparation programs. In a study examining the preparation of CTs in eight different university settings, four of the 23 participants had been trained in some way to work as a CT (Ramanathan \& Wilkins- 
Canter, 2000). Many of same participants indicated that mandatory training would meet with resistance or seem insulting to practicing teachers. CTs did however, appreciate a workshop style preparation meeting to cover basic information and answer questions (Ramanathan \& WilkinsCanter, 2000). Music education programs in Illinois were surveyed, and of the 12 institutions represented in the study, five reported that the institution required a course or in-service for CTs. Other respondents explained that their institutions provided training at one time, but logistics and financial concerns limited the ability to continue with CT training. All of the schools responded that they offer CTs a handbook of required forms and suggestions (Zemek, 2008). This wide variety in CT preparation is understandable given the logistical, financial and practical issues involved. However, teacher preparation programs change and new mandates such as edTPA are added to the list of requirements for STs. Keeping CTs informed and consistent with university policy could support more effective teacher preparation.

Training, especially for mentoring under specific guidelines, has been shown to have a positive impact on STs. According to the Giebelhaus \& Bowman (2002) training of CTs "appear to indicate that cooperating teachers trained in the general principles and practices of mentoring and supervision with a specific framework to guide interactions have a more positive impact on prospective teacher development than those with no training." (p. 12). The responsibility of mentoring is a key component in success of the ST. In general, it was found that, "when teachers serve as CTs without the benefit of training, there is evidence that they are less likely to fulfill the expectations of the role" (Gareis \& Grant, 2014, p. 78). The lack of training creates a disconnect between the university-based lessons and practical classroom experiences of the ST. (DarlingHammond, 2006). Types of training will be addressed in this research along with the CT response to training. 


\section{Impact of Working as a CT}

\section{Impact on CTs in PDS}

Cooperating teachers in a PDS model hold a collaborative position with university faculty in terms of supporting the intern teacher. As described in the goals of the National Association for Professional Development Schools (Brindley, Field \& Lessen, 2008), cooperating teachers offer

their classroom space, collaborative input and professional experience to the intern and university, and receive in return mentoring and professional support from the university staff. This model suggests that cooperating teachers' involvement begins long before an intern enters a classroom and lasts long after that intern has left the classroom. Schussler (2006) suggests that the transformation for cooperating teachers will encourage them to become mentors, decision makers, reflective practitioners, and teacher researchers. This is a potentially powerful change. Although initial research of the effects of the PDS model on cooperating teachers revealed positive benefits (Grossman, 1994; Miller \& Silvernail, 1994; Yendol-Silva \& Dana, 2004) fewer recent studies have been conducted to examine the experiences of cooperating teachers and the dynamic nature of their role as teacher educator. The current study will investigate the impact of acting as a cooperating teacher on the CT in terms of classroom practice, professional development, interaction with the university, and perceived benefits of the experience.

As indicated, CTs provide significant support to the success of student teachers. Several studies indicate that the CT is the most significant influence on student teachers (Griffin et al., 1983; Karmos \& Jacko, 1977; McIntyre \& Byrd, 1998). Student teachers are encouraged, mentored, and professionally influenced through the experience with cooperating teachers.

As detailed in a presentation at the Annual Meeting of the American Educational Research Association in 1995, Clinard examined the experience of 172 cooperating teachers 
working with the University of California Irvine, specifically as related to their participation in a PDS as University Associates. This role expanded beyond interaction with the student teacher and encouraged the cooperating teacher to assume leadership roles with the following expectations:

1. Collaborate with UCI and fellow professional to achieve UCI/PDS goals.

2. Coach and model the most recent techniques for effective instruction.

3. Plan and implement effective teaching strategies for diverse populations.

4. Explore the effective application of current technology.

5. Develop as a professional through active participation in professional organizations, subject matter projects, and/or other professional commitments.

6. Actively explore instructional change through restructuring, educational reform, "action research"

Clinard's research supports the significance of the mentoring role of CTs. This significance of the CT and ST relationship has been noted consistently and in a variety of teacher preparation situations (Chesley \& Jordan, 2012; Clarke, 2001; Killian, \& Wilkins, 2009; Scheetz, Waters, Smeaton, \& Lare, 2005). Specifically, when considering the PDS model of teacher preparation, the roles of the $\mathrm{CT}$ have evolved with the program. Not only does the CT interact closely with the ST, but also with the other members of PDS program to observe, provide feedback, create evaluations, and become a teacher educator (Melser, 2004; Schussler, 2006).

Not only does a CT impact the ST, but also the PDS experience can have lasting impacts for the CT. Studies indicate that CTs in the PDS setting develop innovative teaching strategies, awareness of culturally responsive teaching strategies, enhance communication skills, and renew enthusiasm for teaching (Cobb, 2000; McCormick, Eick, \& Womack, 2013; Shroyer et al., 
2007). After tracking members of the PDS network established through Ohio State University is was determined that CTs benefit from working with diverse people and ideas, grow professionally through taking on new responsibilities, are able to challenge policies, increase reflection on their own teaching, and increase communication with university faculty (Chase \& Merryfield, 1998). Growth through reflection on their own practice was also noted in a study at the University of California, Santa Barbara, as well as the benefit of more time for planning, increased sense of confidences in their own teaching and improved or enhanced curricular strategies (Brink, et al, 2001).

\section{Impact on CT in non-PD}

As indicated previously, the student teaching process came under scrutiny in the 1980s. Since that time, a variety of teacher preparation programs have evolved. The experience of CTs has been examined in various settings with consistent results that indicate working as a $\mathrm{CT}$ can be a positive professional experience.

Similar to the studies with CTs in PDS programs, Tannehill (1989) found that those veteran teachers who assumed the responsibilities of working with STs appreciated the infusion of new teaching ideas, the time to reflection on their teaching as well as a renewed enthusiasm for teaching. As mentors, the CTs found satisfaction in supporting the needs and progress of the STs. These findings have been upheld in a series of studies supporting the concept that acting as a mentor to STs prompts reflection on current teaching methods, classroom design, organization, and a promotes a heightened sense of professionalism (Ganser, 1996; Koerner, 1992). These results have been recognized for CTs at various grade levels and in a variety of school environments. In a mixed-methods study studying the experience of CTs, $157 \mathrm{CTs}$ were 
surveyed and 19 interviewed. Results indicated that working as a CT stimulated reflection, provided opportunities to discuss teaching, and encouraged rejuvenation (Ganser, 1997).

In a comparative study of CT experiences in both PDS and a traditional student teaching model, CTs in both settings indicated that the most important benefit to acting as a CT was the opportunity to reflect upon and improve their teaching. Other positive benefits include more time to work with students individually and increased ability to engage in special projects (Sandholtz \& Wasserman, 2001).

These positive benefits of personal reflection and improved teaching methods were echoed in more recent studies (Busby \& Mupinga, 2007; Franklin Torrez \& Krebs, 2012; GalloFox \& Scantlebury, 2016). These studies also highlight that CTs often enjoy sharing professional knowledge and seeing growth in the STs brings a sense of satisfaction.

\section{Changing Roles of CTs}

Outside of specific benefits to classroom practice, many CTs gain an increased sense of professional agency. Not only do CTs reflect on their practice, share ideas with the ST and gain new insights, but also, the experience "sparked their interest in reading professional articles and attending professional conferences that they might not otherwise have done" (Weasmer \& Woods, 2003). In additional to gathering new information and ideas, CTs often gain experience with new roles in the profession and are prompted to work as agents of change within their classrooms and schools. Coteaching with a student teacher may prompt CTs to engage in similar practices with colleagues or to serve as teacher leaders or guides (Gallo-Fox \& Scantlebury, 2016). This action as a result of working as a CT can prompt growth and change in a school long after the STs have completed their work. 
Increased mentoring for CTs involves increased decision-making in pedagogical situations which can empower CTs as they embrace the complex decisions of the profession. Studies indicate that CTs gain a "sense of power and status as a result of the greater decisionmaking process" (Schussler, 2006). Increased professional agency can also be seen in the desire for CTs to be more involved in the student teaching preparation process (Schussler, 2006).

In a study conducted to examine the experiences of student teaching through the eyes of the CT, Tannehill (1989) interviewed each participant twice, once prior to supervision of the ST and once at the conclusion of the study. One respondent indicated after the conclusion of the student teaching, that, "Cooperating teachers need to have ownership in the teacher certification program to motivate them to do the best job they can do, and to allow them to gain as teachers as well" (Tannehill, 1989, p. 251). In his experience the significant interactions between the CTs and STs elevated the role of the CT to a teacher educator role. Ganser (1996) asserted that "new roles for classroom teachers...may have the potential to take them beyond passive 'cooperation' with university personnel to much more active and proactive roles with greater influence" (p. 4). CTs have a substantial amount of practical and pedagogical knowledge that has not been fully utilized by the university teacher preparation community.

Cooperating teachers, regardless of teacher preparation program, share responsibilities in supporting the development of new teachers. In this shared experience, they too are nurtured in their career. From the emergence of classroom teachers as cooperators in the preparation of new teachers (Clarke, Triggs, \& Nielsen, 2014) to the current push for increased mentoring responsibilities (Ganser (1996), CTs maintain a significant place in the teaching profession and the preparation of future teachers. Their roles are vital in both PDS and traditional programs (DeMonte, 2016; Teitel, 2004). The selection and preparation of CTs varies widely given the 
demands and restraints of the programs involved (Darling-Hammond, 2006; Sawchuk, 2012;

Zemek, 2008). Despite the variety of programs and preparation for working as a CT, CTs not only contribute extensively to the preparation of future teachers, but also receive benefits to their professional growth through the experience of mentoring (Clinard, 1995; Schussler, 2006; Tannehill, 1989).

\section{Analysis and Considerations}

Change in education, even change supported by most stakeholders, takes a considerable amount of time, especially challenging given the engrained structures and expectations of schooling in society. Expectations for teachers are high, and the training requirements are significant; yet more courses are not always the answer. The PDS model and many traditional teacher preparation models advocate for more in-depth and reflective training, much like that of medical training for doctors. Both systems require a significant partnership between educators, practitioners and pre-service individuals. As well, politics, governmental and systematic policy, along with financial concerns serve to either hinder or support such extensive and complicated training programs. A key element in that training is time spent with a cooperating teacher.

Further study needs to investigate the relationship between public policies such as Common Core and edTPA on the climate with-in teacher training facilities. Other potential research investigating the experiences of STs could shed light on improved preparation for those STs as they deal with logistical issues of time management, stress, job hunting, and completing external requirements.

Ultimately, relationships form the foundation for success in the improvement of teaching and learning. However, building the relationships takes time and effort that are not easily afforded to those individuals. The tension between involved parties persists, and as articulated 
by Wiggins (1967), “cooperation-between labor and management, between schools and universities, and between liberal arts and pedagogical components or professional teacher education programs...depends on our individual and collective ability to go for the slow dime instead of the quick nickel" (p. 59). Progress has been made and individuals and collective bodies of educators have in fact envisioned and made real communities of teachers and students that serve both the immediate and long-term needs of those engaged in the pursuit of knowledge.

A lack of current research exists related to the impact of PDS compared to traditional student teaching on cooperating teachers. This dissertation examines the teaching practices, level of engagement, and perceptions of cooperating teachers as they participate in the student teaching programs. The investigation may shed light on the evolving roles of classroom teachers as they become part of the process of educating new teachers. Elements of the research include duration in the PDS or traditional student teaching program, reasons for involvement, perceived impact on their own classroom teaching, suggestions for program improvement, and perceived impact on their position in the field of education as a whole. 


\section{CHAPTER III: METHODS}

\section{Overview}

The purpose of the study was to examine the experiences of cooperating teachers as they engaged with the two different student teaching models: PDS and traditional student teaching. This study examined the preparation of cooperating teachers, their engagement with university faculty, their interactions with a student teacher, and the impact of the process on their own teaching.

Early studies indicated that CTs were experiencing positive professional outcomes as a result of working in the PDS Program (Chase \& Merryfield, 1998; Clinard, 1995; Clinard \& Ariav, 1997; Sandholtz \& Wasserman, 2001). These studies indicated that CTs benefited through increased communication with other education professionals, development of new teaching ideas, and increased time for their own curriculum development. More recent studies indicate similar results about the positive professional impact for CTs (Landt, 2004; Shroyer et al., 2007). CTs in traditional student teaching models also experienced professional benefits as a result of engaging with the student teaching process (Arnold, 2002; Ganser, 1996; Ganser \& Wham, 1998; Weasmer \& Woods, 2003).

However, more research needs to focus on the experience of the CT as they interact with university personnel and the ST. Specifically, preparation of the CT and input from the CT are elements of teacher preparation programs that have not received a great deal of attention. An investigation of the impact of student teaching on the CTs can shed light on the potential professional benefits to the CTs. Given the wide variety of student teaching programs, a comparative study of two programs from the perspective of CTs will provide a more in-depth picture of the programs. 
The results compared the experiences between the student teaching models from the perspective of the cooperating teachers. Information was gathered from both a survey and interviews using a mixed methods research approach.

\section{Research Questions}

The questions reflect the desire to understand the student teaching process through the eyes of the cooperating teacher. This study explored the following questions:

1. How were CTs prepared for the student teaching experience? Is the level of preparation different when preparing for STs in the PDS versus traditional model?

2. How involved are CTs in the teacher preparation process? Is the level of involvement different when working with STs from the PDS versus traditional model?

3. What are the perceptions of professional benefits to the CT? Do the benefits differ when working with STs from the PDS versus traditional model?

4. What are the perspectives of CT related to the impact of the experience on their own teaching strategies? Does this impact differ when working with a ST from a PDS versus traditional model?

5. How might the student teaching process be improved for CTs or STs? Do the suggestions differ when working with STs from a PDS versus traditional model?

\section{Theoretical Foundation}

Activity theory supports the investigation of cooperating teacher experience and development in the PDS and traditional student teaching models. Activity theory, also known as CHAT or cultural-historical activity theory, is a practice-based approach that provides a framework for analyzing professional work practices, and it is well-suited to support the study of learning in the professional education setting (Foot, 2014; Nussbaumer, 2012). Originally 
developed by Vygotsky, Luria, and Leont'ev in the 1920s, AT (activity theory) described the behavior of humans as mediated by objects in the environment (Nussbaumer, 2012). The second and third generations of AT have been developed and popularized by Engestrom who adds that the objects of mediation including "instruments, rules, community, and division of labor mediate or reciprocally influence the achievement of the object as the final outcome" (Nussbaumer, 2012, p. 39). These systems, rules and communities are established in the student teaching models through the structure of the programs, the expectations required to enter the teaching profession, and the nature of learning for students, student teachers, and cooperating teachers.

Activity theory has been used as a framework to study the student teaching experience (Grossman, Smagorinsky, \& Valencia, 1999; Valencia, Martin, Place \& Grossman, 2009). These studies reveal that activity theory helps to explain the complex and varied experiences of student teaching because it takes into consideration that teachers "are developed through problemsolving action carried out in specific settings whose social structures have been developed through historical, culturally grounded action" (Grossman, Smagorinsky, \& Valencia, 1999, p. 4). Cooperating teachers assume particular roles in the student teaching experience and must problem solve for the student teacher as well as for themselves. All of these actions are orchestrated within particular set of social expectations specific to the individual school as well as the PDS or traditional student teaching program. Recognizing the complexity of the relationships and expectations in student teaching will support a thorough investigation of cooperating teachers using a mixed-methods research design.

\section{Research Design and Rationale}

A mixed-methods design was used to examine the experiences of cooperating teachers in two different student teaching programs. A mixed-method approach "involves combining or 
integration of qualitative and quantitative research and data" (Creswell, 2014, p. 14). Examining both comparative quantitative data obtained through a survey and personal narrative data from interviews provided a rich view of the experiences of cooperating teachers in different student teaching programs. Ayrio (2012) explains that a mixed-methods approach "can increase the validity and accuracy of the information" (p. 491). The quantitative results informed the qualitative results, thus strengthening the study as a whole. In addition, a mixed methods approach provided a more comprehensive view of the topic given the in-depth nature of the data analysis.

Although mixed-methods is a relatively new method of research, it offers some advantages in this situation. Choosing mixed-methods allowed for a neutralization of the bias and weakness of both quantitative and qualitative research by combining the methods of investigation (Creswell, 2014). This blending of research methods enhanced both research strategies as the quantitative analysis will inform the qualitative analysis. Onwuegbuzie (2012) suggests that the use of mixed-methods moves research beyond the distinct nature of quantitative and qualitative research into a:

New theoretical and methodological space in which a socially just and productive coexistence among all research traditions is promoted actively, and in which mixed research is consciously local, dynamic, interactive, situated, contingent, fluid, strategic, and generative... conducting research in the radical middle will represent an important first step in conceptualizing, constructing, and maintaining new and different communities of practice or intellectual communities who engage in educational research (p. 194). 
This innovative and dynamic approach was especially useful in this study of an educational situation given the often-neglected subject of cooperating teachers as actors in the student teaching process.

Mixed-methods does have potential drawbacks. Ayrio (2012) explains that a mixed methods approach presents challenges given that it requires expertise in both quantitative and qualitative methods. In addition, a mixed methods approach requires extensive data collection. Recognizing both the advantages and disadvantages of the research approach supported the thoughtful implementation of the procedures.

\section{Procedures}

Specifically, an explanatory mixed methods sequential approach was used in this study. The explanatory sequential approach allowed a level of interaction between the quantitative and qualitative approaches (Creswell \& Plano Clark, .2011).

Specifically, Phase I utilized a cross-sectional survey design in which cooperating teachers responded to an on-line survey related to a student teaching experience for which they served as the cooperating teacher. The questions asked were demographic, related to any training they received for acting as a cooperating teacher, their experience during and after the student teaching in terms of their own teaching, and a program evaluation. Creswell (2014) notes that surveys provide "a quantitative or numeric description of trends, attitudes, or opinions of a population by studying a sample of that population. From sample results, the researcher generalizes or draws inferences to the population" (p. 155-156). This study attempted to gauge the attitudes of cooperating teachers in regards to their experience with different student teaching programs. The data informed the development of Phase II of the study. 
Phase II utilized a semi-structured interview protocol for cooperating teachers who indicated their willingness to discuss the above topics in a more in-depth manner. Interviews are conducted to "understand the world from the subjects' points of view, to unfold the meaning of their experiences" (Brinkmann \& Kvale, 2015, p. 3). Semi-structured interviews are open to a narrative component that allows the interviewee to explain their personal experience. Mischler (1986) explained that the narrative nature of some interviews emphasizes the temporal, social and meaning structures of the interview. This type of interview as research aims to understand the experience and perspective of the cooperating teachers interviewed. Personal interviews more fully informed the results of the surveys given in Phase I and consisted of approximately seven questions.

\section{Participants and Research Setting}

Participants in the study included cooperating teachers in the Professional Development Schools and traditional student teaching placements in a College of Teaching and Learning associated with a Midwestern state university well known for its teacher education program. The School of Teaching and Learning enrolls approximately 3,000 students in undergraduate, graduate, and doctoral programs offering a variety of student teaching experiences including an extensive PDS option. The director of the teacher education program compiled the lists of potential respondents and surveys were forwarded to the CTs. Thus, the participants of both the quantitative and qualitative were self-selected and interviewees were selected using a simple sampling technique.

The participants of this research included current cooperating teachers involved in the Professional Development School and traditional student teaching models of teacher preparation through the Midwestern university. Data were collected from cooperating teachers at various 
levels (ECE-12 $2^{\text {th }}$ grade) and in a variety of schools associated with the university. Cooperating teachers were surveyed regardless of the level and/or discipline that they teach.

\section{Ethical Considerations}

IRB approval was sought to conduct this study and approved in expediated full category. A list of cooperating teachers was generated by the director of the teacher education center at the university. Once permission had been granted to use the list, the survey link was sent to the teachers by email. Consent was sought from the cooperating teachers through a letter that accompanied the survey used to collect data for the study. Participant signatures were not required. Anonymity was maintained through an anonymous survey method and result were secured on a password protected PC. Consent was given if the participant completed and submitted the survey as the research presented no more than minimal risk of harm to subjects and involved no procedures for which written consent is normally required outside of the research context. Cooperating teachers were surveyed regardless of the level and/or discipline that they teach.

For the qualitative portion of the study, if teachers volunteered to participate in the interview portion of the study, all identifying data were maintained using password protected programs. In addition, pseudonyms were used in research reporting.

\section{Instrumentation}

One survey instrument (see appendix 1) was used to gather data to answer the research questions of the study. An electronic survey was developed using online web-based survey software. For the purpose of this study SurveyMonkey, an online survey tool, (http://surveymonkey.com), was used to develop, administer, and analyze the survey. 
The survey was adapted from an instrument used in a dissertation conducted by Dawn Paulson (Paulson \& Latham, 2015) to examine the views of cooperating teachers in relation to their work with student teachers and university supervisors and from a 2016 a pilot study (Bruemmer, 2016) investigating similar concepts. The pilot study indicated that cooperating teachers were interested in helping to support the next generation of teachers, and many of them have invested in the education field through earning higher degrees, participating multiple times as a cooperating teacher, and teaching for multiple years. The CTs expressed a desire to be more involved in the teacher preparation process, and they expressed concerns about elements of the process. These results prompted the current research which aims to delve more deeply into the perspective of the CT. The survey consisted of 26 closed-ended and open-ended items and was divided into five major sections: 1) background information, 2) cooperating teacher experience, 3) participation in the teacher education process, 4) program evaluation, and 5) results of cooperating teacher experience. The cooperating teachers were asked to complete the survey in an electronic format distributed through e-mail.

The quantitative instrument tool was adapted with permission from the dissertation of Dr. Dawn Paulson (Paulson \& Latham, 2015). To support the validity and reliability of the survey, a pilot study was conducted that examined whether the survey items indeed measured the phenomenon under study.

Phase II of the study involved the utilization of a semi-structured interview protocol with cooperating teachers who indicated their willingness to discuss the above topics in a more indepth manner. Interviews attempted to "understand the world from the subjects' points of view, to unfold the meaning of their experiences" (Brinkmann \& Kvale, 2015, p. 3). Data from the semi-structured interviews were used to develop a narrative component from interviewees' 
personal experiences. Personal interviews more fully informed the results from the surveys given in Phase I and consisted of approximately 7 questions (see Appendix B). These questions examined the experience of the CTs before, during and after the student teaching semester. Question aimed to investigate the perspective of the CTs in regards to preparation, interaction with university personnel, impact on $\mathrm{CT}$ teaching and professional practice, and suggestions for program improvements.

\section{Data Collection Procedures}

In this study, quantitative data were gathered first and then analyzed, followed by a qualitative investigation based on those findings. Data were then analyzed as a whole.

The electronic surveys were distributed by email to the cooperating teachers working in conjunction with the Midwestern institution. The cooperating teachers were informed that they could choose to participate by completing the survey on-line and anonymously. The survey was administered to the teachers in the summer of 2017 and remained open for a period of eight weeks. Reminder emails were sent to teachers after 21 and 49 days of administration of the survey. Results were gathered and analyzed quantitatively

A survey question asked the cooperating teachers if they were interested in extending the conversation related to their experience. Teachers who responded positively were contacted to arrange face-to-face interviews at their convenience. The interviews were semi-structured as several questions were prepared in advance, but given the narrative nature of the interview, more questions were asked as the conversation took place. Mischler (1986) notes that the narrative nature of some interviews emphasizes the temporal, social and meaning structures of the interview. This type of interview as research supports the understanding of the perspectives of the cooperating teachers. Interviews were conducted based on availability, lasted no more than 
an hour and were conducted during the fall of 2017. Interviews were recorded and transcribed before analysis. Then narratives were coded and analyzed for themes and patterns such as involvement, improvements, benefits, and preparation.

The full interpretation and discussion followed analysis and comparison of both data sets. In this study, quantitative data were gathered first and then analyzed, followed by a qualitative investigation based on those findings. Data were then analyzed as a whole. Once all analysis has been conducted, interpretation followed.

\section{Data Analysis}

The data gathered from this study were analyzed using quantitative techniques. Statistical Package for Social Sciences (SPSS) was used for the quantitative data analysis. Descriptive analysis including means, standard deviations, frequencies and percentages were used to explore the information obtained from the surveys. In addition, t-tests were conducted to compare results from cooperating teachers in PDS and traditional models.

The open-ended questions and interview answers were analyzed using coding and thematic analysis. Narrative responses provided in the survey were analyzed through grouping comments into categories based on the research questions. For example, to organize the openended responses provided for the topic of professional benefits gained while acting as CT, categories were created based on frequency of response which focused the themes to having extra hands in the room, reflection, and new ideas. This procedure was repeated for each set of open-ended responses provided on the survey.

Interviews were recorded, transcribed, and uploaded into NVivo software for specific coding. Codes were generated using NVivo based on frequency of response and included the categories of impact on teaching, improvements, involvement, preparation, social emotional and 
professional benefits, among others. The results were used to generate trends in the data and were compared to the results and codes generated from the open-ended responses in the survey. Results were organized and described in narrative format.

\section{Reliability and Validity}

Validity and reliability are key factors in both quantitative and qualitative research. In either type of research however, establishing authority requires the researcher to have a degree of familiarity with the content (Edmonson \& Irby, 2008). This study demonstrates an in-depth review of the position and responsibilities of the $\mathrm{CT}$ as seen in the review of literature. After reviewing the literature, it was determined that a mixed-method design study could shed light on under-explored aspects of the differences between PDS and traditional student teaching experiences from the perspective of the CTs.

The quantitative instrument tool was adapted with permission from the dissertation of Dr. Dawn Paulson. To support the validity and reliability of the survey, a pilot study was conducted that examined whether the survey items indeed measured the phenomenon under study. The research examined the perspectives of CTs from both a quantitative survey and a qualitative set of interviews. These multiple sources of data served to justify the themes established in the results. In addition to multiple sources of data, discrepant information will be addressed in the Chapter 5 of the dissertation to support validity. As another measure of validity, the author examined her bias in regards to the content.

To support trustworthiness in the qualitative portion of the study, member checking was conducted with the CTs who were interviewed. After the interviews had been transcribed and a draft of the research results had been created, those documents were sent to the interviewees via e-mail. Responses indicated that a few errors had been made in the spelling of a school and the 
switching of number of years of service in particular grade levels. Other responses indicated that the transcriptions and descriptions were accurate. Errors were corrected.

\section{Researcher Positionality}

I began this research journey as a teacher who had become deeply engaged in the profession through graduate courses, conferences, and acting as a cooperating teacher in several different settings with student teachers from different schools and preparation programs. I became intrigued by the factors that bring people to education, and the factors that maintain and support professionalism. Knowing the complex and changing nature of teacher education, I wanted to investigate the link between university preparation of teachers and the actual classroom experience of teachers. The bridge is cooperating teachers.

This research is personal, as I have been involved in this process as a CT for many STs, and I acknowledge my bias towards the efforts and experience of the CTs. That being stated, in the implementation of this study, I strove to separate my personal experiences from those CTs involved in the study. 


\section{CHAPTER IV: FINDINGS}

The research was conducted using a mixed-methods approach. Therefore, data were collected and analyzed using both quantitative and qualitative methods. Phase I of the research involved gathering data through an on-line survey, and Phase II involved gathering further data through personal interviews. Each phase of the research involved the perspective of cooperating teachers from the 2016-2017 academic year. Phase I recorded the responses of the cooperating teachers to 26 questions, 20 of which were closed- ended questions, while 6 were open-ended questions. A total of 143 teachers responded to the survey. Phase II involved interviews with 5 cooperating teachers, a small sample of the larger collection of teachers who responded to the survey. This more intimate and in-depth conversation provided rich support for the data revealed in the survey.

\section{Phase I: Demographics}

As previously stated, 143 teachers consented to take the survey, this was a $20 \%$ response rate. The low response rate may be explained by the timing of the survey. The survey was sent in late May of 2017, a time when many schools are ending the academic year. Some of the potential respondents might have completed the school year when the survey was initially sent. Also, the follow-up surveys were sent later in the summer, a time in which many teachers are away from school duties and e-mail. Of the 143, 130 responded fully to the survey items. Thirteen teachers who consented to take the survey did not complete all the questions, therefore the responses of those thirteen could not be considered. 
Of those teachers that responded, $105(80.77 \%)$ were female and $25(19.23 \%)$ were male (See Table 1). In terms of the level at which the respondents teach, 43 (33.33\%) teach early elementary Pre-K through $3^{\text {rd }}$ grade, $31(24.03 \%)$ teach elementary grades $4-5,24(18.6 \%)$ teach middle grades 6-8, and 48 (37.21\%) teach high school grades of 9-12.

An investigation of highest academic degree attained by the teachers reveals that 21 $(16.15 \%)$ of those surveyed held a bachelor's degree. About $105(80.77 \%)$ of the teachers responded that they have obtained a master's degree, $3(2.31 \%)$ hold a specialist degree and 1 $(.77 \%)$ holds a doctoral degree. The results indicate that over two-thirds of the respondents have earned an advanced degree. Teaching experience varied among the respondents. $1(.77 \%)$ teacher had been teaching less than 5 years. $25(19.23 \%)$ teachers had $6-10$ years of teaching experience, and $34(26.15 \%)$ possessed $11-15$ years of teaching experience. $70(53.86 \%)$ teachers had been teaching for 16 or more years.

The number of experiences acting as a CT also varied among the respondents. 40 (30.77\%) of the CTs had hosted 1-2 student teachers, while 48 (36.92\%) had hosted 3-5 student teachers, and $42(32.31 \%)$ had hosted 6 or more student teachers.

Table 1

Cooperating Teacher (CTs) Demographic Information

\begin{tabular}{|c|c|c|}
\hline Demographic Information & $\mathrm{N}$ & $\%$ \\
\hline \multicolumn{3}{|l|}{ Gender } \\
\hline Male & 25 & 19.23 \\
\hline Female & 105 & 80.77 \\
\hline \multicolumn{3}{|l|}{ Grade Level Taught } \\
\hline Pre-K -3 & 43 & 33.33 \\
\hline $4-5$ & 31 & 24.03 \\
\hline $6-8$ & 24 & 18.6 \\
\hline $9-12$ & 48 & 37.21 \\
\hline & & Table Continues \\
\hline
\end{tabular}




\begin{tabular}{ccc}
\hline Demographic Information & $\mathrm{N}$ & $\%$ \\
\hline Educational Information & 21 & 16.15 \\
Bachelor's & 105 & 80.77 \\
Master's & 3 & 2.31 \\
Specialist & 1 & .77 \\
Doctorate & & \\
Number of Years Teaching & 1 & .77 \\
Less than 5 & 25 & 19.23 \\
$6-10$ & 34 & 26.15 \\
$11-15$ & 70 & 53.85 \\
$16+$ & & \\
$1-2$ & 40 & 30.77 \\
$3-5$ & 48 & 36.92 \\
$6+$ & 42 & 32.31 \\
\hline
\end{tabular}

Note. $\mathrm{N}=143$. Where total is less than 143 , not all participants responded.

The CTs who responded to the survey shared that they held numerous experiences with student teachers in both the PDS and traditional models. These questions were asked as openended questions and received a variety of responses including several "not sure" or "I don't know" as well as a few responses such as "all." To summarize, in terms of PDS student teacher experiences, 49 CTs had not worked with any PDS STs, 29 had hosted 1 PDS student teacher, 10 had hosted 2 PDS STs, 8 CTs worked with 3 PDS students, 2 CTs hosted 4 PDS students, 6 CTs helped prepare 5 PDS, and 4 CTs have hosted more than 5 PDS STs. Out of the 129 CTs who responded to that question, 14 were either not sure of the program in which their student teacher was enrolled or not able to remember the exact number of STs they had hosted. Seven responses did not offer a numeric value.

Similar responses were given for CTs experiences with student teachers in a traditional program. Of the 127 respondents to this question, 14 CTs had not worked with any STs in a traditional program, 29 had hosted 1 student teacher, $16 \mathrm{CTs}$ indicated that they had worked with 2 student teachers in a traditional program, 17 CTs offered their classrooms to 3 STs, 9 teachers 
hosted 4 student teachers from a traditional program, 9 CTs have worked with 5 STs, and 14 CTs have hosted more than 5 STs. The remainder of the CTs indicated that they were unsure of the number of STs they had hosted or provided non-numeric answers.

Of the student teachers serving with the CTs in the 2016-2017 school year, 64 (49.61\%) were in a PDS program and $65(50.39 \%)$ were in a traditional student teaching model.

\section{Phase I: Research Question One}

How were CTs prepared for the student teaching experience? Is the level of preparation different when preparing for STs in the PDS versus traditional model?

The first research question sought information related to the experience of CTs prior to the year or semester of working with the ST. One survey question asked the CTs to rank the level to which they valued obtaining information related to the ST before the student teacher experience, obtaining specific guidelines for the ST, and obtaining specific guidelines for themselves.

\section{PDS Response}

Cooperating teachers in the PDS program reported that information about the student teacher prior to the field experience was valuable at the following rates: 25 (40.32\%) found it extremely valuable, 31 (50\%) found it somewhat valuable, 4 (6.45\%) did not find it valuable and $2(2 \%)$ found the information somewhat detrimental. Being provided with detailed guidelines about the university expectations of the student teacher was valued at the following rates: 40 (64.52\%) teachers found guidelines extremely valuable, 18 (29.03\%) found guidelines somewhat valuable, 2 (3.23\%) did not find guidelines valuable, 1 (1.61\%) found them somewhat detrimental, and $1(1.61 \%)$ teacher found guidelines for the student teacher extremely detrimental. The third question asked cooperating teachers to report the value placed on detailed guidelines about the university expectations of the cooperating teacher. The guidelines were 
considered extremely valuable by $44(70.97 \%)$ of the respondents, somewhat valuable by 14 $(22.58 \%)$ of the CTs, not valuable by $2(3.23 \%)$, somewhat detrimental by $1(1.61 \%)$, and extremely detrimental by $1(1.61 \%)$ of the CTs involved with the PDS program. See results in table 2.

Table 2

Value of Pre-Student Teaching Information: CTs with PDS STs

\begin{tabular}{ccccccc}
\hline & $\begin{array}{c}\text { Extremely } \\
\text { Valuable }\end{array}$ & $\begin{array}{c}\text { Somewhat } \\
\text { Valuable }\end{array}$ & $\begin{array}{c}\text { Not } \\
\text { Valuable }\end{array}$ & $\begin{array}{c}\text { Somewhat } \\
\text { Detrimental }\end{array}$ & $\begin{array}{c}\text { Extremely } \\
\text { Detrimental }\end{array}$ & N \\
\hline $\begin{array}{c}\text { Information about } \\
\text { the student teacher } \\
\text { prior to the field } \\
\text { experience }\end{array}$ & 25 & 31 & 4 & 2 & 0 & 62 \\
$\begin{array}{c}\text { Detailed guidelines } \\
\text { about the university } \\
\text { expectations of the } \\
\text { student teacher }\end{array}$ & 40 & 18 & 2 & 1 & 1 & 62 \\
$\begin{array}{c}\text { Detailed guidelines } \\
\text { about the university } \\
\text { expectations of the } \\
\text { cooperating teacher }\end{array}$ & 44 & 14 & & & & \\
\hline
\end{tabular}

\section{Traditional Response}

Cooperating teachers in a traditional program reported that information about the student teacher prior to the field experience was valuable at the following rates: 30 (46.88\%) found it extremely valuable, 33 (51.56\%) found it somewhat valuable, and $1(6.45 \%)$ did not find it valuable, and no respondents found the information somewhat or extremely detrimental. Being provided with detailed guidelines about the university expectations of the student teacher was valued at the following rates: $47(73.44 \%)$ teachers found guidelines extremely valuable, 14 $(21.88 \%)$ found guidelines somewhat valuable, 3 (4.69\%) did not find guidelines valuable, no 
respondents found them somewhat or extremely detrimental. The third question asked cooperating teachers to report the value placed on detailed guidelines about the university expectations of the cooperating teacher. The guidelines were considered extremely valuable by $45(70.31 \%)$ of the respondents, somewhat valuable by $17(26.56 \%)$ of the CTs, and not valuable by $2(3.13 \%)$ of CTs involved with a traditional program. See results in table 3 .

Table 3

Value of Pre-Student Teaching Information: CTs with Traditional STs

\begin{tabular}{lcccccc}
\hline & $\begin{array}{c}\text { Extremely } \\
\text { Valuable }\end{array}$ & $\begin{array}{c}\text { Somewhat } \\
\text { Valuable }\end{array}$ & $\begin{array}{c}\text { Not } \\
\text { Valuable }\end{array}$ & $\begin{array}{c}\text { Somewhat } \\
\text { Detrimental }\end{array}$ & $\begin{array}{c}\text { Extremely } \\
\text { Detrimental }\end{array}$ & N \\
\hline $\begin{array}{c}\text { Information about } \\
\text { the student teacher } \\
\text { prior to the field } \\
\text { experience }\end{array}$ & 30 & 33 & 1 & 0 & 0 & 64 \\
$\begin{array}{c}\text { Detailed guidelines } \\
\text { about the university } \\
\text { expectations of the } \\
\text { student teacher }\end{array}$ & 47 & 14 & 3 & 0 & 0 & 64 \\
$\begin{array}{c}\text { Detailed guidelines } \\
\text { about the university } \\
\text { expectations of the } \\
\text { cooperating teacher }\end{array}$ & 45 & 17 & 2 & 0 & 0 & 64 \\
\hline
\end{tabular}

\section{Comparing PDS and Traditional Programs}

An independent samples t-test was conducted to compare the extent to which the CT preparation experience differed on the average for CTs who worked with PDS STs and traditional STs. The results showed no statistically significant differences between the experience of the CTs who worked with PDS STs $(\mathrm{M}=1.46, \mathrm{SD}=.783)$ and the CTs who worked with STs in a traditional program $(\mathrm{m}=1.31, \mathrm{SD}=.559)$ in regards to level of preparation through 
detailed guidelines given about the university expectations of the student teacher, $t(124)=1.28$, $p=.202$.

Similarly, there was no statistical difference between the experience of the CTs who worked with PDS STs and the CTs who worked with STs in a traditional program in regards to level of preparation through detailed guidelines given about the university expectations of the cooperating teacher, $t(124)=.633, p=.528$.

An additional survey question inquired about the level of involvement in a training or preparation program designed for the CT. Training here is investigated as part of the preparation to serve as a CT. Of the $125 \mathrm{CT}$ s who responded 8 (6.4\%) were extremely involved, 31 (24.8\%) were somewhat involved, and $86(68.8 \%)$ were not involved. There was no significant difference between the level of involvement for training for CTs who worked with PDS STs $(\mathrm{M}=2.53, \mathrm{SD}=.645)$ and those who worked with traditional $\mathrm{STs}(\mathrm{M}=2.71, \mathrm{SD}=.551), t(123)=-$ $1.69, p=.092$. This reveals that there was no significant difference between the experience of CTs with STs in the PDS and Traditional programs in terms of specific training or preparation for the CTs.

\section{Phase I: Research Question Two}

How involved are CTs in the teacher preparation process? Is the level of involvement different when working with STs from the PDS versus traditional model?

Research question two investigated the experience of the CT in regards to their level of involvement with the preparation of the student teacher. To examine the experience, CTs responded to questions about their level of involvement as viewed through four factors: communication with the university before the student teacher semester, selection of curriculum 
for the student teachers, instructional methods for the student teacher, and consultation with the university instructors.

\section{PDS Response}

Cooperating teachers in both programs reported the extent to which they were involved in the preparation of student teachers. CTs in the PDS program reported that $14(22.58 \%)$ were extremely involved in communication with the university before student teaching, 35 (56.45\%) were somewhat involved, and 13 (20.97\%) were not involved. In regards to the selection of curriculum for the STs, CTs in the PDS program revealed that 39 (62.9\%) were extremely involved, 8 (12.9\%) were somewhat involved, and 14 (22.58\%) were not involved. CTs in the PDS program reported the following involvement with instructional methods for STs: $31(50 \%)$ were extremely involved, 20 (32.26\%) were somewhat involved, and $11(17.74 \%)$ were not involved. The final involvement question inquired about the level of consultation with the university instructor. Results for CTs in the PDS program reveal that 16 (25.81\%) were extremely involved, 34 (54.84\%) were somewhat involved and 12 (19.35\%) were not involved.

\section{Traditional Response}

For the same set of questions, CTs in traditional programs reported 9 (14.29\%) were extremely involved in communication with the university before student teaching, 47 (74.6\%) were somewhat involved, and $7(11.11 \%)$ were not involved. In regards to the selection of curriculum for the STs, CTs in traditional programs revealed that $45(71.43 \%)$ were extremely involved, 6 (9.52\%) were somewhat involved, and $12(19.05 \%)$ were not involved. CTs in traditional programs reported the following involvement with instructional methods for STs: 33(52.38\%) were extremely involved, $21(33.33 \%)$ were somewhat involved, and 9(14.29\%) were not involved. The final involvement question inquired about the level of consultation with 
the university instructor. Results for CTs in traditional programs reveal that $21(33.33 \%)$ were extremely involved, 33 (52.38\%) were somewhat involved and 9 (14.29\%) were not involved. Results are reported in Table 4.

Table 4

Involvement for CTs with STs in PDS and Traditional Programs

\begin{tabular}{|c|c|c|c|c|c|}
\hline Item & STs & $\begin{array}{l}\text { Extremely } \\
\text { Involved }\end{array}$ & $\begin{array}{l}\text { Somewhat } \\
\text { Involved }\end{array}$ & $\begin{array}{c}\text { Not } \\
\text { Involved }\end{array}$ & $\mathrm{N}$ \\
\hline \multirow{2}{*}{$\begin{array}{l}\text { Communication with } \\
\text { university before }\end{array}$} & PDS & 14 & 35 & 13 & 62 \\
\hline & Traditional & 9 & 47 & 7 & 63 \\
\hline Selection of & PDS & 39 & 8 & 14 & 62 \\
\hline curriculum for the STs & Traditional & 45 & 6 & 12 & 63 \\
\hline \multirow{2}{*}{$\begin{array}{l}\text { Instructional methods } \\
\text { for the STs }\end{array}$} & PDS & 31 & 20 & 11 & 62 \\
\hline & Traditional & 33 & 21 & 9 & 63 \\
\hline \multirow{2}{*}{$\begin{array}{l}\text { Consultation with the } \\
\text { university instructors } \\
\text { of STs }\end{array}$} & PDS & 16 & 34 & 12 & 62 \\
\hline & Traditional & 21 & 33 & 9 & 63 \\
\hline
\end{tabular}

\section{Comparing PDS and Traditional Programs}

No statistical differences were found between the experience of the CTs who worked with PDS STs and the CTs who worked with STs in a traditional program in regards to involvement related to communication between the university and the CT before student teaching, $t(123)=.148, p=.883$.

Again, no statistical difference was found between the experience of the CTs who worked with PDS STs and the CTs who worked with STs in a traditional program in regards to involvement related to the selection of curriculum for student teachers, $t(123)=1.009, p=.315$. 
Also, in regards to involvement related to instructional methods for student teachers, $t$ (123) $=.438, p=.662$. No statistical significance was found in regards to involvement related to consultation between the university and the CT, $t(123)=1.049, p=.296$.

To understand more thoroughly the CTs' perspective on their involvement in student teaching, CTs were also asked if they would like to have input on the design of the student teaching field experience. Those CTs involved in the PDS program reported that 37 (59.68\%) were interested in being more involved in the design of student teaching, 18 (29.03\%) were not interested and 7(11.29\%) provided other comments. Those CTs in the traditional programs reported $42(67.74 \%)$ were interested in being more involved in the student teaching process, 17 (24.72\%) were not interested, and 3 (4.84\%) provided other responses. Results follow in Table 5. Table 5

CT Desire to Have Input on Student Teaching Field Experience

\begin{tabular}{lccccccc}
\hline & Yes & $\%$ & No & $\%$ & Other & $\%$ & N \\
\hline PDS & 37 & 59.68 & 18 & 29.03 & 7 & 11.29 & 62 \\
Traditional & 42 & 67.74 & 17 & 24.72 & 3 & 4.84 & 62 \\
\hline
\end{tabular}

Of those who responded other, comments were collected. CTs who most recently hosted STs in Traditional programs explained, "It depends on how he/she progresses," "I would, but I am retiring," and "I don't feel the need because the supervisor ensures university and state standards are met." CTs who most recently hosted STs in the PDS program commented, "It is important to get feedback from the CTs to know what works and what doesn't," "I do have input as the student teacher is in my classroom. So, they better perform up to my standards," "I try to give feedback to the supervising teacher when I see something that my ST may need more exposure or support," "I think the CT has as much influence on the student teaching experience as he or she wants already," "I believe I already have input on the design of the field experience. 
As an experienced classroom teacher, I know what experiences and tasks a new teacher needs to master to become a successful teacher. I and my team work hard to teach and prepare our PDS students," "Some input would be nice. El Ed got to give feedback at the end of the year at a meeting with the supervisor. ECE doesn't get the same opportunities they do," and "I like the current structure."

\section{CT Suggestions for Greater Involvement}

A related question asked the CTs in what ways might they become more involved in the preparation of the student teacher before they enter the classroom for student teaching.

PDS response. Responses for CTs working with STs in a PDS program were coded into three main categories of early contact with the $\mathrm{CT}$ for procedural information, early contact with the $\mathrm{CT}$ for curriculum information, and CT desire to participate more closely with the university.

Of the CTs involved in the PDS program, 49 provided extended responses to this item. A desire for more time to prepare with the ST was evident as a theme in the responses. Additionally, CTs expressed a desire to be more deeply involved in process of preparing the STs.

Results are represented in Table 6.

Table 6

CTs with STs in PDS Programs Desire for More Involvement

\begin{tabular}{|c|c|}
\hline Category & CT Comment \\
\hline $\begin{array}{l}\text { Early contact with } \\
\text { CT for procedural } \\
\text { information }\end{array}$ & $\begin{array}{l}\text { "It would be nice if the student teachers were able to come into the } \\
\text { classroom early to see how the teachers have things set up. If they begin } \\
\text { their experience in the fall, it would be nice for them to stop in at the end } \\
\text { of the previous year to meet and see the classroom and observe. It may } \\
\text { eliminate some of their stress when they have a lot being tossed at them } \\
\text { at the beginning of the year." }\end{array}$ \\
\hline
\end{tabular}

Table Continues 


\begin{tabular}{|c|c|}
\hline Category & CT Comment \\
\hline & "I would meet with him/her to discuss behavior and discipline." \\
\hline & $\begin{array}{l}\text { "Meeting with them in the weeks before to discuss grading, classroom } \\
\text { management strategies, etc" }\end{array}$ \\
\hline & $\begin{array}{l}\text { "Giving them an opportunity to set up a classroom or close down a } \\
\text { classroom and set classroom rules and expectations because they walk } \\
\text { into a class that has established rules." }\end{array}$ \\
\hline & $\begin{array}{l}\text { "Have the student teacher spend time throughout the year before so they } \\
\text { can observe both beginning, middle and end of the year processes." }\end{array}$ \\
\hline \multirow{2}{*}{$\begin{array}{l}\text { Early contact with } \\
\text { CT for curriculum } \\
\text { information }\end{array}$} & $\begin{array}{l}\text { "It is important that the ST has a voice in the curriculum map. The } \\
\text { sooner you can get the ST in to help plan, the better." }\end{array}$ \\
\hline & $\begin{array}{l}\text { "Be very clear of curriculum content and levels within that content for } \\
\text { instructional differentiation." }\end{array}$ \\
\hline $\begin{array}{l}\text { CT desire to } \\
\text { participate more } \\
\text { fully with } \\
\text { university }\end{array}$ & $\begin{array}{l}\text { "I would love to come to the university and cover all the expectations } \\
\text { within the content area as well as the traits in my opinion help for a } \\
\text { successful experience. Too many student teachers come into this last } \\
\text { semester having little understanding of the importance of knowing that } \\
\text { what they learned in the classroom must be retained! They have seemed } \\
\text { to learn content material for the semester, not retaining for their future } \\
\text { students. I would also stress personality and communication are key to } \\
\text { the success. Even the amount of hours after the class day seem to be a } \\
\text { shock to the students." }\end{array}$ \\
\hline
\end{tabular}

Traditional response. CTs working with STs in Traditional programs responded to the same inquiry regarding their desire to be more involved in the preparation of the student teacher. The responses were coded into the categories of general familiarity with the ST placement, early contact with the CT for procedural information, early contact with the CT for curriculum information, and a desire for the CT participate more fully with the university. Of the CTs who had worked in the traditional program, 45 responded to this survey item. The themes for this set of CTs was similar to the CTs involved in the PDS program, namely more time to prepare with 
the ST before student teaching and a desire for greater involvement with the university. Results are represented in Table 7.

Table 7

CTs with STs in Traditional Programs Desire for More Involvement

\begin{tabular}{|c|c|}
\hline Category & CT Comment \\
\hline \multirow{7}{*}{$\begin{array}{l}\text { General familiarity } \\
\text { with the ST } \\
\text { placement }\end{array}$} & $\begin{array}{l}\text { "I had a letter and an email and then she showed up to teach. Maybe a } \\
\text { future student teacher could visit the classroom prior to beginning." }\end{array}$ \\
\hline & $\begin{array}{l}\text { "It would be beneficial if the student teachers could spend some time } \\
\text { observing in class before they begin their experience." }\end{array}$ \\
\hline & $\begin{array}{l}\text { "The student teacher should really come in and observe the classroom } \\
\text { ahead of time. Meeting and communicating before the semester of } \\
\text { student teaching is the best." }\end{array}$ \\
\hline & $\begin{array}{l}\text { "Roundtable discussions with soon-to-be student teachers, observations } \\
\text { of classes before they begin student teaching, a mentor type role in their } \\
\text { last semesters" }\end{array}$ \\
\hline & $\begin{array}{l}\text { "If given the opportunity, I would be happy to host a pre-service teacher } \\
\text { for multiple observations so he/she then comes into the classroom a bit } \\
\text { more familiar with how things work in my room." }\end{array}$ \\
\hline & $\begin{array}{l}\text { "I would offer my classroom for them to observe for a while so they } \\
\text { understand the type of environment they are entering. I would like to } \\
\text { meet prior to the start date to discuss district protocols and/or programs } \\
\text { that are required." }\end{array}$ \\
\hline & $\begin{array}{l}\text { "It might be nice for the student teacher to spend some time in the } \\
\text { classroom the semester before they student teach to help them become } \\
\text { more familiar with the classroom and school." }\end{array}$ \\
\hline \multirow{2}{*}{$\begin{array}{l}\text { Early contact with } \\
\text { CT for procedural } \\
\text { information }\end{array}$} & $\begin{array}{l}\text { "By planning things for the student teacher to do in order to get the } \\
\text { classroom ready for the school year." }\end{array}$ \\
\hline & $\begin{array}{l}\text { "Giving them student/population background information and } \\
\text { regulations/procedural information about our school." }\end{array}$ \\
\hline
\end{tabular}




\begin{tabular}{|c|c|}
\hline Category & CT Comment \\
\hline \multirow{5}{*}{$\begin{array}{l}\text { Early contact with } \\
\text { CT for curriculum } \\
\text { information }\end{array}$} & $\begin{array}{l}\text { "I would like them to participate in the beginning of the school year } \\
\text { activities (setting up the classroom, setting procedures, learning the class, } \\
\text { etc). I would also like the ST to be required to observe me and report on } \\
\text { this several times before they begin their experiences in my classroom." }\end{array}$ \\
\hline & $\begin{array}{l}\text { "I would like to have more meetings and time to go over curriculum and } \\
\text { expectations." }\end{array}$ \\
\hline & $\begin{array}{l}\text { "Some advance time to review and prepare lesson planning and } \\
\text { curriculum with the student teacher." }\end{array}$ \\
\hline & $\begin{array}{l}\text { "Let them see the curriculum they are going to be working with before } \\
\text { they actually start student teaching." }\end{array}$ \\
\hline & "Curriculum ideas" \\
\hline $\begin{array}{l}\text { CT desire to } \\
\text { participate more } \\
\text { fully with } \\
\text { university }\end{array}$ & $\begin{array}{l}\text { "The mentor teachers could be involved in online forums that address } \\
\text { some of the issues involved in this process." }\end{array}$ \\
\hline
\end{tabular}

\section{Phase I: Research Question Three}

What are the perceptions of professional benefits to the CT? Do the benefits differ when working with STs from the PDS versus traditional model?

To understand the perceived benefits to CTs, the short answer responses were first filtered based on the program in which the most recent ST has been placed. CTs in the PDS program provided 52 responses, and CTs in the traditional program provided 48 responses. Responses were then analyzed using a word cloud production created by Survey Monkey, and further analyzed by the researcher through coding and grouping comments based on thematic similarities. 


\section{PDS Response}

In response to the survey question asking what benefits were gained from serving as a CT, CTs with PDS STs frequently provided the following terms: extra hands, reflection and new/fresh/current ideas.

To elaborate on those common themes, the concept of having "extra hands" in the room was explained by various comments such as "I was able to spend time helping my Special Ed students more" and "additional support with small groups." These were examples of the beneficial effects of having a PDS ST. Another CT commented, "and the extra teacher in the rooms allows me to provide more effective reading and math workshop experience." In addition, another CTs commented that, "I also greatly appreciate the extra support my students get because there is another set of hands in the room!" and "Extra hands allow for more diversified lessons and small groups." Similarly, a CT noted that "I could reach/develop more students through small grouping with two adults in the room." In general, the CTs found a benefit in having another adult to help facilitate lessons and/or support the needs of students. The benefit was directed toward student support and learning.

Reflection also appeared multiple times in the responses from CTs with STs in the PDs program. One teacher noted, "I like to model what I ask of my ST so this allowed me to take inventory to determine how I was doing and what areas needed attention." Similarly, other CTs noted that hosting a ST, "makes me review my own teaching" and "It continuously makes me think about both my student teacher's performance as well as my own." Another CT commented, "I gained an appreciation for all the things I do naturally in and out of the classroom for my students." Many teachers simply commented, "I enjoyed reflecting on my practices" or the term "reflection" merely appeared as a benefit. 
Another frequent response by CTs who hosted STs in a PDS grogram revealed that new, fresh, or current ideas proved to be a benefit. Many of those comments reflect a sense of renewing older ideas such as, "After teaching for over 25 years, I gain a fresh perspective" or “changing methods after 32 years." Other CTs comment. "new teachers bring new energy and differing perspectives" and "helps me stay current with certain methods and ideologies." Many CTs commented that they were able to gain new ways of doing things in their classrooms such as, "A new perspective on their craft and I am always tweaking my approach" and "keeps me trying new things." Most of the comments are linked to benefits that help the CT change or modify a current technique.

Although not specifically represented in the word cloud, several comments spoke to the CTs appreciation for a chance to help support the profession of teaching and new teachers. For example, one CT noted, "It is helpful to work with someone who is just beginning to grapple with planning, grading, etc." Another CT commented, "I was able to share the realistic view of the classroom." Similarly, a CT replied, "I learned how to guide, step in when needed, but also allowed my student teacher to learn hard lessons before going into their first year." This pride in preparing future teachers well was also noted with, "I'm able to help make sure that our future teachers are in this profession for the right reasons." On a related note, another CT commented that, "I love being able to talk about what I do and I why I do it. There are many ways to teach..." These comments suggest that the CTs are invested in the profession, excited about sharing it with others, and hope that the next generation of teachers will continue to be positive leaders for students. 
One comment revealed a negative experience. The CT explained, "I am not sure there have been any benefits. Having a student teacher is hard work and not always a positive experience." This comment did not have further explanation.

\section{Traditional Response}

When examining the comments made by CTs who worked with STs in a Traditional program, the benefits of extra hands, reflection, new ideas, and support for new teachers also appeared frequently. However, differences were noted in the frequency of the term technology which was more specifically mentioned with CTs who had STs in a traditional program. A word cloud was also generated for the responses of the CTs in the traditional program.

The benefit of extra hands or another adult was also noted among CTs with STs in traditional programs. CTs commented, "another trained adult to work with kids! The students receive more attention more often than when I am in the classroom alone" and "Two bodies in the room was helpful when working with small groups. Two sets of eyes and different personalities allowed us to reach more students." Similarly, another CT noted, "I enjoyed the extra eyes, ears and hands." Having the extra adult allows CTs "more opportunities to work with individual students and small groups." Once again, as reflected in the statements of the CTs working with PDS STs, the extra hands help to support student learning. This reveals a similarity between the CTs in both programs.

Reflection also appeared numerous times as a stated benefit for CTs working with STs in a Traditional program. One teacher explained, "It's caused me to take a good hard look at everything I'm doing in my classroom to evaluate how my management can be streamlined and to determine what educational strategies seem most beneficial to my students." Reflection also encouraged one CT to "become a stronger teacher in the end and to look more closely at some of 
my practices." Other CTs noted that acting as a CT, "presented the opportunity to deeply reflect on the pedagogy in the classroom," and "allowed me to reflect on my own practice by articulating the why behind my actions." As seen with the previous set of CTs, the benefits of reflection are geared toward supporting classroom practice and student learning.

CTs working with STs in Traditional programs also acknowledged that learning new ideas or gathering new techniques was a benefit of acting as a CT. Many CTs commented that working with a ST gave them, "new skills," or "new lessons and techniques," or new resources f or my classroom." CTs also noted that they received the benefit of "new ways to look at the same curriculum" and "motivation to continue to explore new and innovative ways to enrich the educational experiences of my students." The new and innovative techniques were at times designated or related to technology, something that was not noted as frequently by CTs working with PDS STs. For example, one CT explained, "I gained insight on the amount of note taking and computer based technology that is used to progress monitor kids." In addition, one teacher noted that a benefit of hosting a ST from a traditional program was gaining "new and exciting technology."

Finally, another similarity between the CT groups was the benefit of working with and supporting new individuals in the profession. CTs noted, "positive professional relationships" and "understanding how to help beginning teachers." Another CT expressed pride in "Watching a student teacher grow." Simply stated, one CT commented, "I love the mentoring aspect of being a CT." Again, these comments reveal a dedication to the field of education. 


\section{Phase I: Research Question Four}

What are the perspectives of CT related to the impact of the experience on their own teaching strategies? Does this impact differ when working with a ST from a PDS versus traditional model?

To understand the potential impact of serving as a CT on the CTs' own teaching practices, teachers were asked how the experience had changed their classroom instruction, curriculum activities and/or procedures. CTs working with PDS STs provided 56 responses, and CTs working with STs in traditional programs provided 49 responses. Again, the CTs' responses were filtered for those CTs who had worked with STs in PDS programs and those who had worked with STs in traditional student teaching models.

\section{PDS Response}

CTs who hosted STs in a PDS program commented frequently that their experience supported reflection, new ideas, technology and the capacity to serve as a role mode. Many CTs appreciated the time to reflect on their teaching practices, which encouraged change through comments such as, "Seeing some of the methods and protocols used by the student teacher has allowed me to analyze my own style and alter things that have gotten stale." Another teacher commented, that working as a CT, "Made me review my own teaching and change methods." Reflection also supported CTs re-evaluation of their own work as reveled in comments such as, “it helps me reflect on my own teaching practices" and "Being a CT makes me look at why I do things" and "it helps me reflect on the how and why of my decisions in the classroom."

CTs also expressed that due to working with STs, new ideas were presented, shared and at times incorporated into classroom practice. One CT explained that, "a few of my student teachers have come up with innovative lessons, classroom management techniques, or 
organizational techniques that I have then incorporated into my classroom." CTs also commented that, "The student teachers bring new ideas for presenting curriculum into the classroom that I can use in the future." Another CT explained, "Being a CT has definitely helped me refresh some skills or things that I may have used in the past, and suggest them to the ST. I've also learned some new and creative activities developed by my STs." Associated with new techniques, technology was mentioned several times. Many CTs mentioned that, "It motivated me to learn more technology" and "I have learned more up-to-date uses of technology."

Several CTs appreciated the experience of working as a CT because it encouraged them to teach with integrity. For example, one CT explained, "I find that I'm better at lesson planning when I have a ST. The accountability to be prepared and to be a good role model helps me to be my best." Similarly, another teacher commented, "The ST helps keep me on my game and be prepared to be a good role model every day." For one CT, the experience, "forces me to be purposeful in my classroom structures."

A few CTs experienced no change, as reflected in the comments, "not much change for me" and "The experience hasn't changed what I do." One CT did comment that the nothing had changed, and that the ST did not have a positive impact as explained, "my student teacher was awful, unprepared and eventually quit the program never saying good bye to the kids." These neutral or negative experience were presented less frequently than the positive experiences.

\section{Traditional Response}

CTs who hosted STs in a Traditional program shared similar comments related to reflection, gaining new ideas, and acting as role models. As seen in the first group of CTs, reflection prompted change for the CTs who hosted STs in Traditional programs as well. For 
example, one CT explained, "The experiences have prompted greater reflection for me on how/why I do things." Similarly, another CT noted, "Having a student teacher made me more aware of my own instructional strategies and seek out ways to further improve my teaching." Some of the reflection had a direct impact on students as revealed by a CT who noted, "It made me more aware and observant of my own practices. It helped me see, from an outside point of view, what my students were struggling with and needed more instruction in." Another CT commented that, "I believe the experience reminded me to continuously be reflective as well as challenge myself to dissect the purpose of what I am choosing to do with students and how that impacts assessment."

New and innovative ideas were also mentioned as changes or an impact as a result of acting as a CT. Many of the CTs found the new ideas applicable to their classrooms even after the student teaching experience had concluded. As noted by one CT, "I have actually used several of the items my ST created in my classroom. It is nice to have an infusion of new activities." Similarly, another CT explained, "My ST created a ton of awesome, student centered activities that I will continue to use in the years to come." Specific strategies or techniques were mentioned such as pacing, formative assessment, use of visuals such as anchor charts, and surveys for students were mentioned as new techniques incorporated by the CTs.

Serving as role model encouraged change for some CTs as revealed in the comment, "To be involved in this process a teacher has to be more focused and organized to model this for the student teacher." Another teacher noted, "Having a novice teacher observing me makes me more aware when I am teaching. I will make a point to vary my instruction, use lots of higher level questioning techniques, and a variety of behavior management strategies." 
As seen in the CT group who worked with PDS STs, a few CTs who hosted STs in traditional programs had neutral or negative experiences. For example, "It hasn't changed it too much. I try to fit the student teacher into our procedures what we do here since they are only with us for a short amount time" and "little to none" in terms in change. The one negative experience was explained as, "It is always my objective to let the ST completely take over the classroom, trying new management techniques, lesson formats, etc. However, the last student teacher I had was so ill-prepared for the experience that this was not truly possible." Similar to the previous group, the negative comments appeared less frequently than the neutral or positive comments.

\section{Phase I: Research Question Five}

How might the student teaching process be improved for CTs or STs? Do the suggestions differ when working with STs from a PDS versus traditional model?

\section{PDS Response}

When asked to provide suggestions for improvement, CTs in the PDS program offered 52 responses, and CTs in traditional programs offered 49 responses. Teachers who worked with STs in a PDS program offered a variety of improvements related to the structure of the program, preparation of the student teachers, challenges especially with edTPA, suggestions for more take over time for the student teacher, and improved connections with the university. The information has been coded and analyzed and the results are presented in Table 8 together with the CTs' comments to highlight each category or theme. Categories for improvement include a desire for contact between the ST and the CT before student teaching which could help the ST

prepare for fully for the teaching experience. CTs also noted a desire for STs to possess more indepth knowledge of content and procedural/classroom management which they perceive would 
improve the student teaching process. The time spent on edTPA and other logistical issues

proved to be a major concern for $\mathrm{CTs}$, who perceived that these requirements interfered with the progress of the student teacher. On a related note, CTs suggest that STs spend $n$ increased amount of time with students in full take-over. A final suggestion for improvement revealed a desire from the CTs for increased communication with the university in terms of guidelines for the program and support for the student teaching experience.

Table 8

CTs with STs in PDS Program Suggestions for Improvement

\begin{tabular}{ll}
\hline Category of Comment & \multicolumn{1}{c}{ Cooperating Teacher Comment } \\
\hline $\begin{array}{l}\text { ST contact with CT } \\
\text { prior to teaching }\end{array}$ & $\begin{array}{l}\text { "I think it would be nice to have more time before class starts to } \\
\text { meet and share expectations and ideas for the upcoming school } \\
\text { year." }\end{array}$ \\
& "More than one 3-5 day stretch in the first semester (PDS) \\
& considering how much time they spend in the classroom." \\
& "It would be beneficial if the student teacher had the opportunity to \\
& visit my classroom 2-3 times prior to the start of the following \\
school year. That would help him/her to see the end in mind." & \\
& "It would be helpful if the student teacher was able to visit the \\
school ahead of time on a day when school is in session. I assume \\
that the majority of student teachers know, before they leave for the \\
summer, which school they will be placed at, so that should make it \\
possible." \\
"I would like to be able to interview the candidate to make sure that \\
we are a good fit." \\
"I think the student teachers need to be better with content they are \\
teaching and setting up basic units, choosing important concepts to \\
teach, and making up homework assignments and tests"
\end{tabular}

Table Continues 


\begin{tabular}{ll}
\hline Category of Comment & Cooperating Teacher Comment \\
\hline & $\begin{array}{l}\text { "Have some idea of classroom management. Be able to prepare a } \\
\text { lesson from start to finish. Understand that you cannot "wing it" you } \\
\text { need to know what you are teaching before you teach it." }\end{array}$ \\
$\begin{array}{l}\text { "The amount of paperwork the student teacher needs to do now is } \\
\text { paperwork/edTPA }\end{array}$ & $\begin{array}{l}\text { not an example of what teachers really need to do. Eliminate some } \\
\text { of the "busy work" that the student teachers need to do so they can } \\
\text { concentrate on the curriculum they need to teach." }\end{array}$ \\
& "Less interference from the university would help. This last student \\
& teacher had so much on his plate that teaching and completing \\
paperwork from the university became obviously very stressful." & \\
& "Reduce EDTPA requirements-too much time lost from student \\
teaching experience because of it, disruptive to flow of \\
responsibilities in student teaching."
\end{tabular}

"I do feel that the expectations placed on the student teachers for the EdTPA were a bit high and maybe even unrealistic. They had a ton of requirements to meet and then were given time off from student teaching to get it done. In "the real world" teachers have a lot to get accomplished but we don't get time off to make it happen. We find the time or it isn't done well. I think for student teaching the expectations shouldn't be so high that they need time off."

"Again, it's all about the preparation with less focus on [ed]TPA paperwork. The current student teacher missed key moments to work and observe out of school functions due to his need to "work" on his [ed]TPA bureaucracy. I thought the experience of student teaching was to engage, not sit behind a computer and type a 50page paper. Have that project due prior to student teaching during the junior year during education classes or at the university schools? That makes sense to me."

More time for ST in full take over

"For student teacher more time in take over."

"Student teachers would be better off if they began with us at the beginning of the year instead of starting 1 week after school begins. Also, the schedule for the classroom duties they need to assume needs to be adjusted...it does not account for Thanksgiving week, etc. And waits too long for them to fully take on the classroom." 


\begin{tabular}{ll}
\hline Category of Comment & \multicolumn{1}{c}{ Cooperating Teacher Comment } \\
\hline "I also think they should work until the end of the year, so they can \\
see the process of shutting down the classroom and all the \\
paperwork, etc. involved." \\
"Depending on the level the student plans to teach, provide a longer \\
time in that specific placement." \\
"16 weeks at the same school." \\
"The university supervisors need to be more involved in a weekly \\
schedule of what is happening. With my last student teacher there \\
was not enough involvement with the university and there was a \\
major issue that I ended up dealing with most of it on my own." \\
"More information from the university before the student teacher \\
actually started would be helpful as far as what the university \\
expected of me." \\
"I would like clearer guidelines. Although I love the flexibility of it, \\
at times, it seems almost too loose, which can make it difficult to \\
make sure that all student teachers are getting the right experience. \\
It also gives the student teacher more wiggle room, which can be \\
hard at times to navigate as a CT." \\
"Needs to be better communication between the college of \\
Education and the secondary programs (like business, fcs, ag, etc)" \\
"More communication between the cooperating teacher and the \\
University colleague." \\
"My student teacher would have benefited from clearer expectations \\
as to what constituted an A for her own grade, which she was very \\
concerned about."
\end{tabular}

\section{Traditional Response}

Teachers who worked with STs in Traditional programs suggested similar improvements, but with more mention of the challenges of edTPA and the perceived need for more time for the ST to be involved in classroom take over. Specifically, CTs mentioned a desire for the STs to 
visit the classroom before student teaching to help them prepare with general knowledge of classroom, curriculum and expectations. CTs also noted a desire for STs to hold a greater depth of content knowledge along with classroom management strategies. Similar to the CTs in the PDS program, edTPA and other paperwork frustrated the CTs in the traditional program. CTs suggest less time dedicated to completing these tasks would improve the program. More time for the STs to spend in full take over was another suggestion for improvement. CTs explain that more time with a class in student teaching can better prepare those STs for taking on the responsibilities of their own classroom in the future. The final suggestion offered by CTs in the traditional program revealed a desire for increased connection with the university, which is another similarity to the CTs in the PDS program. This desire for greater connection extends to both the STs and CTs for support and input during the student teaching process. Results are summarized in Table 9.

Table 9

CTs with STs in Traditional Program Suggestions for Improvement

\begin{tabular}{|c|c|}
\hline Comment Category & Cooperating Teacher Comment \\
\hline \multirow[t]{4}{*}{$\begin{array}{l}\text { ST contact with CT prior to } \\
\text { teaching }\end{array}$} & $\begin{array}{l}\text { "If it would be possible for a student teacher to do an internship } \\
\text { prior to student teaching to get to know the students and } \\
\text { procedures, it would be helpful." }\end{array}$ \\
\hline & $\begin{array}{l}\text { "Prior contact with the student teacher to create lessons and } \\
\text { assessments for prior approval" }\end{array}$ \\
\hline & $\begin{array}{l}\text { "As I mentioned, getting the student teacher more familiar with } \\
\text { their classroom by observing/working in the classroom the } \\
\text { semester before student teaching is beneficial." }\end{array}$ \\
\hline & $\begin{array}{l}\text { "Visits prior to the ST experience. I really enjoyed the PDS } \\
\text { program and how it was laid out." }\end{array}$ \\
\hline
\end{tabular}




\begin{tabular}{|c|c|}
\hline Comment Category & Cooperating Teacher Comment \\
\hline Content Knowledge & $\begin{array}{l}\text { "Again, the most critical component I've observed recently is a } \\
\text { need for greater depth of content and greater understanding of } \\
\text { strategies that elicit deeper thinking from our students." }\end{array}$ \\
\hline \multirow{3}{*}{$\begin{array}{l}\text { Procedural Knowledge/ } \\
\text { Classroom Management }\end{array}$} & "Having discussions about classroom management" \\
\hline & $\begin{array}{l}\text { "I would like to see ST candidates educated a little more on the } \\
\text { importance of speaking and acting in a positive manner with } \\
\text { children." }\end{array}$ \\
\hline & $\begin{array}{l}\text { "I think there should be a facet dedicated to classroom control } \\
\text { and behavior management." }\end{array}$ \\
\hline \multirow[t]{7}{*}{$\begin{array}{l}\text { Reduction in } \\
\text { paperwork/edTPA }\end{array}$} & $\begin{array}{l}\text { "Get rid of edTPA! The poor student teachers are so } \\
\text { overwhelmed with that! They aren't really able to focus on the } \\
\text { nitty gritty of the day to day responsibilities in the classroom } \\
\text { until that is over. Then all they care about is graduation." }\end{array}$ \\
\hline & $\begin{array}{l}\text { "Get rid of EdTPA. It is an incredible waste of time and takes } \\
\text { away valuable prep time for the classroom." }\end{array}$ \\
\hline & $\begin{array}{l}\text { "Ed TPA is important. However, I am not certain the pressure } \\
\text { of finishing Ed TPA and a full load of classes is the best option } \\
\text { for success in both." }\end{array}$ \\
\hline & $\begin{array}{l}\text { "I think it would be helpful if the student teacher was under less } \\
\text { pressure to perform all the paperwork involved as well as the ed } \\
\text { TPA portion that was added. These pressures put so much on the } \\
\text { student teacher that it forces them to not be so enthusiastic about } \\
\text { the educational field." }\end{array}$ \\
\hline & "All of the paperwork-- ugh." \\
\hline & $\begin{array}{l}\text { "Not that it can change, but EdTPA is at a very inconvenient } \\
\text { time. My student teacher was prepared to teach and had started } \\
\text { taking over some subjects but then needed to remove herself for } \\
\text { most days in order to complete her write-ups. It was very } \\
\text { confusing for the students." }\end{array}$ \\
\hline & $\begin{array}{l}\text { "The EdTPA took quite a bit of time away from the student } \\
\text { teacher's direct involvement in the classroom. It also caused } \\
\text { quite a bit of stress for her." }\end{array}$ \\
\hline
\end{tabular}

Table Continues 
"The regulations of Ed TPA absolutely need to be adjusted so that the student teacher completes this at the end of student teaching, not the start."

"Student teachers should be required to be more hands-on during their first few weeks in the classroom. My last ST spent the first few weeks working on gathering information for and composing EdTPA writing. She did not use this time to observe my teaching methods and get to know the flow of our classroom. I feel this was a major downfall of the entire experience and affected her performance throughout."

"The idea of the ED TPA at the start of student teaching is difficult. It is when the teacher is growing and trying different things. It should be an end of the student teaching when they have started planning lessons and more prepared to talk about their teaching."

More time for ST in full take over

\section{"More teaching time for the ST"}

"Have the student teacher begin at the start of the semester if possible, instead of entering in later in the semester."

"Student teachers should be prepared to start contributing to the classroom as soon as they start. They should not be solely observing at any time."

"I feel that the more time they have in the classroom, they more prepared they will be for their career as an educator. There are many "safety" nets in place that keep them from having a full load for a longer period of time."

"I had a fantastic experience with my last student teacher; however, since she was in the traditional program, we did have a discussion prior to her leaving about how she wished she had more time with me and our kids."

"I think that student teachers might need to stay a little longer so that they can really see the entire process. I think my last student teacher was only here for 6 weeks -- it felt rushed. I wanted to make sure he experienced many different aspects of the job." 


\begin{tabular}{|c|c|}
\hline Comment Category & Cooperating Teacher Comment \\
\hline \multirow[t]{10}{*}{$\begin{array}{l}\text { Connection with the } \\
\text { university }\end{array}$} & $\begin{array}{l}\text { "Student teachers need to be trained to be open and use the } \\
\text { cooperating teacher as their main resource when questions arise. } \\
\text { Also, I felt that the university supervisor was very biased and } \\
\text { unopen to my concerns." }\end{array}$ \\
\hline & $\begin{array}{l}\text { "Expectations from the university need to be clearer for both the } \\
\text { student teacher and the CT." }\end{array}$ \\
\hline & $\begin{array}{l}\text { "The students go to seminars and perhaps inviting the } \\
\text { cooperating teachers to a seminar day would be beneficial so } \\
\text { everyone can hear and learn what others are doing/not doing. } \\
\text { Would help to share what is working and what is not for the } \\
\text { teachers as well as the student teachers." }\end{array}$ \\
\hline & $\begin{array}{l}\text { "More regularly scheduled check-ins and observations by a } \\
\text { university representative, and a clear process that the student } \\
\text { teacher is expected to go through in terms of lesson planning." }\end{array}$ \\
\hline & $\begin{array}{l}\text { "More communication between the cooperating teacher and the } \\
\text { university supervisor, or any university connection." }\end{array}$ \\
\hline & "More observation feedback from supervisor." \\
\hline & "more communication with the University supervisor" \\
\hline & "higher expectations of student teachers on the University end" \\
\hline & $\begin{array}{l}\text { "I think more contact with the university would be excellent. I } \\
\text { think having the student teacher here for observations before the } \\
\text { period begins would be beneficial." }\end{array}$ \\
\hline & $\begin{array}{l}\text { "More communication between university and CT. I'd love to be } \\
\text { sent a binder with all necessary materials already loaded, rather } \\
\text { than hoping I've printed everything I needed from an } \\
\text { emailed/shared drive." }\end{array}$ \\
\hline
\end{tabular}

Phase 2: Interviews with Cooperating Teachers

Phase II of the study, which was qualitative in nature, involved interviews with cooperating teachers regarding their personal experiences of acting as CTs, specifically their preparation for working as a $\mathrm{CT}$, connection with the university during the process, benefits they 
perceived from the experience, and differences they noted between programs and suggestions for improvement. Interviews were conducted to allow for a more personal and in-depth understanding of the experience of CTs in the student teaching process. A total of five CTs were interviewed. While this sample size may appear to be a small subset of the 143 respondents who responded to the survey distributed in Phase I, the information provided and the analysis generated from this procedure provided depth to the outcomes obtained in Phase I of the study. The researcher made a good faith effort to interviews CTs from both teacher preparation programs. However, due to limited response and availability, four of the five interviewees represented the traditional student teaching, while only one represented the PDS experience. This investigation is not able to generate any statistical comparisons, but it did generate in depth insight into the perspective of cooperating teachers who work with STs in both the PDS and Traditional programs.

Three interviews were conducted in face to face situations, and two were conducted via the use of Skype. All interviews were audio recorded and transcribed. Cooperating teachers provided detailed descriptions of their experiences with one or more student teachers, covering topics related to the challenges faced during the student teaching process, the benefits of the program for the cooperating teachers, critiques of the experiences and discussion of changes in education. Interview transcriptions were analyzed with the support of the NVivo software. Nodes or categories were generated based on the research questions and topics that arose during the course of the interviews including, differences between PDS and Traditional programs, edTPA, impact on teaching, improvements suggested by CTs, involvement of the CT with the student teaching process, preparation for acting as a CT, preparation of ST, professional benefits, and social emotional issues. 


\section{Biographical Information of the Interviewees}

A brief biographical sketch is presented for each interviewee. Pseudonyms have been used to protect the privacy of the participants. Each interviewee shared their own personal experiences of hosting STs. Demographic information revealed that all the interviewees hold a Master's degree and range in teaching experience between six and twenty-five years. One of the interviewees teaches at the high school level, while the others teach grades ranging from 2-6. Four of the five were most recently involved with STs in a traditional program. The teachers have varying degrees of experience acting as CTs given that I CT had just recently hosted her first ST, and the other CTs had hosted more than 2 STs during their time as teachers. (See Table 9).

The first interviewee, Sarah Robinson, teaches mathematics at the high school level and holds a Master's Degree. She had been teaching for more than 20 years, primarily at the same school. During her time there she has hosted several student teachers from area colleges and universities in both Traditional and PDS programs. She shared a deep compassion for the lives of students outside the classroom, and expressed a desire for greater emphasis of socialemotional issues as a tool to help future teachers be prepared for the realities of the classroom.

Carol Smith currently teaches science at the $5^{\text {th }}$ grade level. During her more than 20 years as a teacher, she has hosted between 3 student teachers, all from Traditional programs. Recently earning a Master's Degree in STEM education, she works to integrate literacy skills into science classrooms. Smith expressed concern for the lack of maturity and problem-solving skills in both her students and the student teachers that she has hosted. Overwhelming and disconnected mandates for classroom teachers were also a concern expressed by Smith. 
While teaching $3^{\text {rd }}$ graders, Lynn Reynolds earned her Reading Specialist Master's and has been teaching for 6 years total. She recently worked with her first student teacher. She had a unique perspective on the experience because she had completed the PDS program herself, and worked with a student teacher in the traditional program. She appreciated the time and capacity to reflect on her teaching, but was concerned about the timing of the placement during the Fall semester.

Brittany Stevens has been teaching 5 th grade for 7 years after spending 1 year as a $2^{\text {nd }}$ grade teacher. She, too, has earned a Master's degree. During her time as a teacher she has worked with 3 student teachers, all in the traditional program. Her experiences have been positive with student teachers, but she expressed concerned related to the support provided by the university supervisor. She also encourages student teachers to spend as much time as possible in full take over to prepare them for their own classroom.

Abby Russell has been teaching for 18 years, 7 years in $5^{\text {th }}$ grade and the last 11 years as a $2^{\text {nd }}$ grade teacher. She holds a Master's degree and has hosted 2 student teachers in the traditional program with plans to host a third in the Spring of 2018. Abby enjoys working with other professionals in the field and has benefited from creative and innovative student teachers. Her experiences with university supervisors have been exceptional including a situation in which the university supervisor (US) took a student under his wing to support his learning. 
Table 10

Cooperating Teachers Interviewed

\begin{tabular}{llllll}
\hline Teacher & $\begin{array}{l}\text { Grade } \\
\text { Level- } \\
\text { Current }\end{array}$ & $\begin{array}{l}\text { Highest } \\
\text { Degree }\end{array}$ & $\begin{array}{l}\text { Years } \\
\text { of } \\
\text { teaching }\end{array}$ & $\begin{array}{l}\text { Number } \\
\text { of STs }\end{array}$ & $\begin{array}{l}\text { PDS or } \\
\text { Traditional }\end{array}$ \\
\hline Sarah Robinson & $9-12$ & MS & 25 & $6+$ & Both \\
Carol Smith & $5-6$ & MS & 24 & 3 & Traditional \\
Abby Russell & 2 & MS & 18 & 3 & Traditional \\
Brittany Stevens & 5 & MS & 8 & 3 & Traditional \\
Lynn Reynolds & $2-3$ & MS & 6 & 1 & Traditional \\
\hline
\end{tabular}

The following provides a narrative description of the findings from the interviews after coding and thematic analysis. The first five categories directly address the research questions, followed by other topics generated through the course of the interviews: preparation to act as a $\mathrm{CT}$, involvement of the $\mathrm{CT}$ with the student teaching process, professional benefits, impact on CT teaching, improvements for the programs as suggested by the CTs, additional categories of edTPA, ST preparation and social emotional issues.

\section{Preparation for Acting as a CT}

When asked to explain if they felt prepared to serve as CTs, interviewees responded with mixed answers, some feeling well prepared and supported, others not. In general, teachers reported receiving information from the university in regards to the student teaching experience, and some CTs expressed the desire to have more specific preparation.

Abby Russell felt well-supported with information and contact from the university, explaining, "I did, and it seemed like every day I was getting another e-mail, almost to the point where I was like, OK I am inundated, but it was always very easy to go back and refer to, OK surely this was in one of those e-mails, and go back and find to somewhere." 
Carol Smith expressed mixed reactions when considering all her experiences with STs. Comparing multiple interactions with the university, she stated:

I would say some years I have [felt prepared]. I would say this past year I really didn't. Some of the supervising teachers have been very clear... I would say sometimes, I don't get that... and so therefore sometimes it is hard for me to know where to move my student teacher, where to push or where to encourage or what their focus is for that particular time. So sometimes I feel like we are just winging it. I had one year when I would say the communication was very clear and it made it a lot easier. And otherwise I would say the communication has not been as good, and I have had difficulty knowing where were or what we should be doing.

Lynn Reynolds described that she received a packet of information before the student teaching semester and that she was able to gather suggestions from colleagues who had hosted student teachers.

\section{Involvement of the CT with the Student Teaching Process}

CTs also expressed varying levels of involvement with the student teaching process, specifically in terms of interactions with the university or university supervisor during the student teaching experience. One CT reported an excellent and supportive experience with the university supervisor (US), while another reported a "rocky" relationship between the US and the $\mathrm{ST}$, as the CT attempted to navigate the experience given that relationship. Yet another reported that the information was helpful, but a more involved connection was desired.

Abby Russell recalled one extremely memorable interaction with a university supervisor, who also happened to be the father of another teacher in her building. She explained: 
We had a fantastic experience...He was phenomenal. He would come and sit with the kids during their lessons. He is a big, tall guy, and he would get in those little chairs. And... I'm gonna cry. We had this one little guy who was struggling a little bit, and he went to the nth degree. He made contact with the parents and took him for ice cream...

In contrast, Brittany Stevens reported that the working relationship with her university supervisor was not as supportive of the student teacher. Not only did the situation cause frustration for the ST, but also the CT herself. Stevens explained:

That was a rocky relationship. I don't feel like she was very supportive of my ST... The criticisms that she would give were very vague and didn't leave a whole lot for her to grow from, and it often ended up being a big frustration when she would come for observations. Um, part of that experience...it ended up being a lot of stress on my plate, too because... she would find herself having to take time out of her morning, the morning that her supervisor was coming, to re-send paper work, um..the supervisor couldn't keep track of it or would say she couldn't access it. It was very clear that [ST] had gone through and done all the steps she was supposed to, but the supervisor was not...I'm not sure what the situation was, but it was very frustrating...

Lynn Reynolds appreciated the support that she received as a CT and would have welcomed even more interaction the US. Reynolds explained, "I think if the supervisor had checked in with me a little more often and said, and she was great, don't get me wrong, but if she had checked in with me and said typically at this point in the year the ST is demonstrating these behaviors, are you seeing this with yours, if not let's talk about how you could get her there." 


\section{Professional Benefits}

The comments shared by the interviewees reflected the professional benefits gathered from the survey in terms of having extra hands in the rooms, providing time for reflection, and gathering new ideas for the classroom.

For instance, Abby Russell recalled the partnership as very positive, and she explained, "I know this is going to sound very simple, but just an extra set of hands. They were for the most part...very helpful and very willing to listen to ideas, but the kids loved them...Just to have a partner and someone to work with." Lynn Reynolds also mentioned the positive aspects of getting to work more with her students during student teaching. She revealed:

getting to work with the kids more one on one because I had the time to... and then I was able to really focus in on certain parts of my instruction... so I felt like it made me stronger, um I was able to dig deep and be more um intentional about the things that I was doing.

The positive benefits of reflection came up multiple times during the interviews. CTs were pleased to have the time to reflect on their practice and make adjustments as need. Brittany Stevens recalled:

I love hosting ST...um not because once they are in full take over they take a lot of pressure for me, but I love hosting them because it helps me reflect on what I am doing as a teacher, and not only gives me ideas it sometimes solidifies what is good practice and can be shared or just things I need to change and I can take actually tips from new teachers, so that is really an awesome thing to see. 
Carol Smith also noted the positive aspects of reflection in her comments, "It also makes me way more reflective on my own practice because as you explain it to someone else, like why do I do this? And maybe that's kind of out dated, that doesn't make sense. So, it forces me to evaluate the things that I am doing, which I really like."

CTs enjoyed gaining new teaching ideas and perspectives. Sarah Robinson shared the adage that teachers are proficient at "stealing" ideas from one another as she explained, "You saw some good ideas and stole...every good teacher is a good thief. So, stealing some ideas, particularly with technology. They know a lot more about that than I do, as far as the latest apps and stuff that they have used in their classes." Robinson also shared that having conversations about instruction was valuable for her to see new perspectives while reminding her of her own skills.

\section{Impact on CT Teaching}

Related to professional benefits, CTs commented that the experience of acting as a CT impacted their teaching through offering new ideas and giving new perspectives that they carried into classes after the ST had completed the student teaching.

Abby Russell noted that:

So, like I said there were many things that they brought to the table. New, fresh ideas and fresh approaches to things...like I said a lot of the CC Math techniques that they had...Yeah, a lot of their creative lessons...or things they made. Things I was already doing, and um...there were a couple things, they said what if we do it this way, or we learned about this or that technique. We made little manipulatives and little things and laminated them, and of course I kept them. 


\section{Improvements for the Student Teaching Process}

CTs offered several suggestions for improvement to the student teaching process. Improvements were suggested in terms of connection with the university, need for an increase in full take over time, content preparation for the STs, and program timing of student teaching.

Brittany Stevens suggested that more support could be provided for the ST explaining, "I do wish that in this case, with this particular ST, um she needed some little bit more stringent guidelines as to when take over should start and end. She was rather hesitant to begin taking over more and more subjects, even though I did feel like she was ready." Stevens also expressed a desire for more professional development from the university for herself as a mentor teacher, as she stated, "I personally have been searching for some professional development in mentoring... um I feel like I do a pretty decent job of you know coaching them along, but to have some formal maybe offered by the university would be really great."

Stevens and others suggested that student teachers would benefit from more time in full take-over of the classroom. They expressed that this could prepare the ST more completely for taking on the responsibilities of their own classrooms in the future. Specifically, Stevens suggested:

I do feel like her actual take over could have been longer. I don't feel, and I felt this way about all 3 of my ST, I don't feel like there needs to be that weaning off time, especially when they are in the spring... when they are handing the class back over to the teacher...I don't feel like that is necessary, and that the full take over could be extended by a couple of weeks to get them more experience. 
Carol Smith was concerned with the amount and quality of content requirements for STs before they enter a classroom. Her perspective comes from working with $5^{\text {th }}$ grade students and STs in the elementary program. Her own preparation was not through elementary education. She expressed the desire for a stronger base in content for the STs as described here:

I wasn't in the elementary program when I went through, full disclosure I was trained as a junior high teacher, so we had a lot more content in our background, but I guess at the elementary... I don't know if this is true or if it's outdated, but we have to take PE at the elementary, and art and music... If those requirements are outdated...it seems to me like your time might be better spent learning the math, the science, the social studies content if you are an elementary teacher...I think you have a lot of disjointed material. What are you going to actually teach? I would buffer up the content teaching that is available to elementary teachers.

At a structural level, Lynn Reynolds suggests that student teaching in the fall semester poses challenges for both the CTs and STs. Reynolds explained, "Fall is hard, and I know we can't control when they student teach, but I was still trying to figure out who my students were, and at the same time trying to teach the student teacher about who they students are and how to work with them, so that was difficult."

\section{edTPA as a Complication}

CTs expressed concern and frustration over the edTPA requirements for the STs. Sarah Robinson explained, "that was just an overwhelming thing." The time away from the classroom concerned Robinson as well, as she commented: 
I got a note from the university supervisor saying that the deadline was coming up, and if I wanted to take a few classes off her plate... and I thought OK, I don't have a problem with that, but you are teaching and you are doing this, but hello in the real world you do have to juggle responsibilities, and heaven forbid the day you have a husband and kids and have to juggle those, and ailing parents, and so, and I don't know how much of a realistic view you need to give them.

Her suggestion was to do away with the edTPA requirement. Lynn Reynolds also suggested the elimination of the edTPA requirement while recognizing the fact that the university and CTs do not control that decision. She stated:

Get rid of EdTPA, but I know I can't say that...I know we don't have that power, but I do know that was something that was a lot of stress on her part um it consumed her for the weeks she was working on that. I think it is great that the university provides the release time for her to work on it... but she did have those days built in and that was good for her to immediately reflect on everything that she did, so keep the data, don't get rid of that.

\section{Preparation of ST}

CTs also provided suggestions for the preparation of STs before the student teaching semester that were unrelated to curricular/content concerns. Abby revealed concern about professional attire and behavior. Abby Russell suggested an increased awareness of:

"professionalism...just knowing how to be respectful toward your CT...I mean I want them to come to me, I want them to trust me, and I want to help them, but also not becoming so laxed that you expect things....and I know work ethic is not something that 
you can teach, but maybe something that you can promote just a little bit more. And then of course you know the dress.

Another area of ST preparation that concerned CTs was the need for an increase in the ability to deal with social emotional needs of the students in the classroom.

Abby Russell discussed issues related to tone of voice and the potential impact that can have on children. She suggested, "just learning how to talk to children. It really is crazy, you know you can say things, two different ways to children, and it can affect a child so differently." Sarah Robinson noted that much of the job of a teacher is helping students cope with life outside of the academic content. She explained:

It's been terrible to tell these kids but your day in college is $90 \%$ material and $10 \%$ interaction and in school it's the opposite...the amount of math I do in the course of the day is minute compared to trying to get.. Johnny didn't have breakfast, trying to find him a granola bar, this one doesn't have a coat, this one didn't get enough sleep. They don't focus on that enough. And it's the social-emotional that is getting to be such a huge part of teaching. And they would really do themselves a benefit if they relaxed on all the hoops they had to jump through and focus a little more on giving them some skills that way.

\section{Differences Between PDS and Traditional Programs}

A few of the CTs interviewed were able to compare the experiences of those in PDS and Traditional student teacher preparation programs to provide. Lynn Reynolds had completed her teacher preparation in a PDS program and had recently hosted a ST in a Traditional program. When asked about difference that she noticed, Reynolds responded: 
So, I felt like I was more prepared leaving school, like leaving my ST experience because I had been there for a full year. And she did full time take over for 3 weeks, where and I was thinking about it, I feel like I was in full time take over for a month maybe 6 weeks, it felt like a really long time, but the 3 weeks seemed so short. And I actually had emailed the professor or supervisor, is this correct, only 3 weeks... my experience was just longer, like the things that I needed to work on from the beginning, I had so much more time to work on it... Whereas with my ST, I felt like it was so fast, it just flew.

Sarah Robinson has hosted several student teachers from various programs and local colleges and universities. Her experiences revealed that the PDS students displayed a great level of commitment to the student teaching process. Reynolds explained, "They [2 STs in PDS] were both phenomenal. Some of my other ones were passable, but those $2 \ldots$ the thing I noticed was they weren't afraid to get there early and to stay late and to do whatever it takes for kids. Whereas the kids on the 8 or 16-week plan, they were 8:05-3:35." This difference may be due to the isolated behavior of these student teachers, not a reflection of the program itself. But ultimately, Robinson expressed a tendency to host PDS STs over students enrolled in other programs. 


\section{CHAPTER V: CONCLUSIONS, IMPLICATIONS, AND RECOMMENDATIONS}

\section{Introduction}

This chapter includes five sections. As a review, the first section will summarize the purpose, participants, and study design. The second section summarizes the findings of the research in both the quantitative and qualitative modes of the study. Discussion and implications for teacher training programs are provided in section three. The fourth section discusses the limitations encountered with this study. Finally, the fifth section provides recommendations for future studies.

\section{Summary of the Study}

Current teacher preparation in the United States includes both university classroom-based pedagogical preparation and clinical K-12 classroom experience. This structure provides theoretical support for the practical application of teaching methods. The two-pronged approach evolved through a variety of teacher education methods developed in individual normal schools and state-run programs dating from the late 1800s (Grant \& Murray,1999; Pushkin, 2001; Tozer, Violas, \& Sense, 1993). Structures vary to provide the classroom-based portion of teacher preparation, some programs involve a sixteen-week student-teaching experience, while others involve a year-long approach to the experience. In both situations, research indicates that the cooperating teacher plays a significant role in the preparation of the student teacher. Several studies indicate that the $\mathrm{CT}$ is the most significant influence on student teachers (Griffin et al., 1983; Karmos \& Jacko, 1977; McIntyre \& Byrd, 1998). Student teachers are encouraged, mentored, and professionally influenced through the experience with cooperating teachers. Not only does the CT have an impact on the ST, but also the process of acting as a mentor and leader has an impact on the CT. This study sought to examine the impact on CTs and explore the 
differences between traditional and PDS teacher preparation programs through the perspective of the cooperating teachers.

To examine the differences between the two programs from the perspective of the CTs, a mixed methods sequential study was conducted. Phase I involved an on-line survey of cooperating teachers, followed by Phase II which involved interviews of five cooperating teachers who had completed the survey. Participants in Phase I of the study included cooperating teachers in both professional development school and traditional student teaching placements in a large teacher preparation program in a Midwestern university. The director of the teacher education center compiled lists of potential respondents and surveys were forwarded to the CTs via email. Data were collected from cooperating teachers at various levels (ECE-12 ${ }^{\text {th }}$ grade) and in a variety of schools associated with the university. Cooperating teachers were surveyed regardless of the level and/or discipline that they taught. In response to a final question on the survey, cooperating teachers consented to being contacted for a potential interview. Five of those who volunteered to be interviewed were selected based on availability. The five teachers were interviewed with a semi-structured interview protocol in face-to-face and internetbased video program formats.

\section{Summary of Findings}

Most CTs expressed satisfaction with the level of preparation they received before serving as a CT. Specifically, the first research question sought information related to the experience of CTs prior to the year or semester of working with the ST. One survey question asked the CTs to rank the level to which they valued obtaining information related to the ST before the student teacher experience, obtaining specific guidelines for the ST, and obtaining specific guidelines for themselves. These results were divided and examined based on the most 
recent ST arrangement, either PDS or traditional. No statistical significance was found between the experiences of CTs with traditional STs and those who hosted STs in the PDS program. An additional survey question inquired about the level of involvement in a training or preparation program designed. No significant difference was noted between the experience of CTs with STs in the PDS and Traditional programs in terms of specific training or preparation for the CTs. After discussing the preparation that CTs received before hosting a ST, the interviewees revealed that the majority felt well-prepared given information from the university and contact with a university supervisor. One $\mathrm{CT}$ expressed mixed feeling of preparation when comparing multiple experiences that she has had acting a as CT.

Another finding suggests that CTs have a desire to be more involved with the ST process. For the purpose of this study, involvement was determined based on communication with the university before the student teaching, selection of curriculum for the STs, input on instructional methods for the STs, and consultation with the university instructors. No statistical differences were found between the experiences of CTs hosting STs in programs studied. Interviewees experiences varied in terms of interaction with the university. One reported an extremely helpful and supportive relationship, while another categorized the relationship as "rocky." Yet another interviewee expressed a positive experience, but one that could have been more involved. However, when CTs were asked if they would like to be more involved in the student teaching process, the majority of CTs in both programs answered in the affirmative. More specifically, CTs responded that they would enjoy more contact with the ST before student teaching to discuss content and procedures, and CTs desired an opportunity to participate more fully with the university in the preparation of student teachers. 
CTs reported a variety of professional benefits as a result of serving as a CT. To examine this issue, CTs were asked to provide short answer responses that inquired about the professional benefits they received from the experience of acting as a CT. In summary, the CTs who worked with STs in the PDS program most frequently commented that the professional benefits involved having an extra set of hands in the room, time for reflection, and new/fresh/current ideas. CTs who hosted STs in traditional programs also frequently noted that they benefited from having extra hands and time for reflection. Differences occurred in the mention of supporting new teachers in the field and a specific mention of technology. The interviewees' comments supported the survey results. When asked about professional benefits, the five teachers also explained that extra hands in the room were helpful for supporting instruction, the experience provided time for reflection on teaching practices, and new ideas were infused into the classroom.

Another finding reveals that CTs' own classroom practices were impacted by the experience of serving as a CT. To understand the impact on CTs' teaching, CTs who completed the survey provided short answer responses explaining how the experience of working as a CT had changed their classroom instruction, curriculum activities and/or procedures. In summary, CTs who hosted STs in the PDS program commented frequently that their experience supported reflection, new ideas, technology, and the capacity to serve as a role model. CTs with STs in traditional programs shared similar comments related to reflection, gaining new ideas, and acting as role models. Interviewees commented in ways consistent with the survey results. CTs appreciated new ideas and new perspectives that remained with them after the student teaching experience. 
CTs suggested a variety of improvements for the student teaching programs. Among CTs with STs in the PDS program, categories for improvement included a desire for contact between the ST and the CT before student teaching and a desire for STs to possess more in-depth knowledge of content and procedural/classroom management which they perceive would improve the student teaching process. The time spent on edTPA and other logistical issues proved to be a major concern for CTs, who perceived that these requirements interfered with the progress of the student teacher. On a related note, CTs suggest that STs spend an increased amount of time with students in full take-over. A final suggestion for improvement revealed a desire from the CTs for increased communication with the university in terms of guidelines for the program and support for the student teaching experience.

Teachers who worked with STs in traditional programs suggested similar improvements, but with more mention of the challenges of edTPA and the perceived need for more time for the ST to be involved in classroom take over. Specifically, CTs mentioned a desire for the STs to visit the classroom before student teaching to help them prepare with general knowledge of classroom, curriculum and expectations. CTs also noted a desire for STs to hold a greater depth of content knowledge along with classroom management strategies. Similar to the CTs in the PDS program, edTPA and other paperwork frustrated the CTs in the traditional program. CTs suggest less time dedicated to completing these tasks would improve the program. More time for the STs to spend in full take over was another suggestion for improvement. CTs explain that more time with a class in student teaching can better prepare those STs for taking on the responsibilities of their own classroom in the future. The final suggestion offered by CTs in the traditional program revealed a desire for increased connection with the university, which is 
another similarity to the CTs in the PDS program. This desire for greater connection extends to both the STs and CTs for support and input during the student teaching process.

Interviewees echoed the concerns shared in the survey results. Improvements were suggested in terms of connection with the university, increased full take-over time for STs, content preparation for STs, and program timing of student teaching.

\section{Discussion and Implications}

Using activity theory or CHAT as the theoretical lens for this comparative study of student teaching programs was supported by previous studies with a similar framework (Grossman, Smagorinsky, \& Valencia, 1999; Valencia, Martin, Place \& Grossman, 2009). These studies reveal that activity theory helps to explain the complex and varied experiences of student teaching because it takes into consideration that teachers "are developed through problemsolving action carried out in specific settings whose social structures have been developed through historical, culturally grounded action” (Grossman, Smagorinsky, \& Valencia, 1999, p. 4). Cooperating teachers assume particular roles in the student teaching experience and must problem solve for the student teacher as well as for themselves. All of these actions are orchestrated within particular set of social expectations specific to the individual school as well as the PDS or traditional student teaching program. This study reveals that teacher preparation is complex, and from the perspective of the CT involves varied factors that impact the experience such as timing, personalities, program specific requirements, and levels of involvement. Through examining the interconnected nature of the humans and systems involved in the preparation of teachers with CHAT as the lens, this study demonstrates the complicated interplay of factors.

Results demonstrated that no statistically significant differences exist in the experiences of CTs when working with STs in the PDS or traditional programs. Differences were noted 
between specific student teaching experiences given the timing of the placement, length of ST take-over, and individual interactions between CTs and STs, university supervisors and faculty. External factors such as edTPA impacted the experience more than was anticipated.

Cooperating teachers responded with comments consistent with the research in regards to benefits of acting as a $\mathrm{CT}$ such as new and innovative ideas, time for reflection, and pride in supporting the profession (Grossman, 1994; Koerner, 1992; Miller \& Silvernail, 1994). When given the opportunity, CTs provided insightful and specific suggestions for improving the student teaching experience for all members involved.

The results suggest implications for teacher education programs, both PDS and traditional, in regards to interactions among the stakeholders in the process. Implications are suggested within four specific concepts: consideration of the PDS model's goal of shared responsibilities with $\mathrm{CTs}$, relationships between the university supervisor and the $\mathrm{CT}$, the methods of executing the edTPA regulations within student teaching, and CT desire for greater involvement in the teacher preparation process.

\section{PDS Goals of Shared Responsibilities}

The stated goals of the PDS program include shared responsibilities and reciprocal development for STs and CTs (Brindley, Field \& Lessen, 2008). The results of this study do not reflect a sense of shared responsibility between the CTs and the university. No difference was noted between the PDS and traditional programs from the CT perspective. The implication for PDS leaders is an examination of the connection developed between the university and K12 setting, especially the CTs. Previous studies indicate that a strong connection between the university and K12 schools supports learning for all stakeholders (Baker, 2011; Cuchiara, 2010; Teitel, 2004). There is potential for a stronger and more beneficial partnership. The CTs in this 
study indicated a desire to meet with the students in the semesters before student teachers. This is an opportunity for the university to strengthen the partnership with increased contact and dialogue with CTs throughout the teacher preparation program.

\section{Relationship with the University Supervisor}

Results suggest that the university supervisor acts as a direct and vital link between the ST/CT team and the university. When the relationship is strong, the process tends to work well with members feeling a great deal of support. However, when the relationship is weak, confusion and frustration are present in the experience. Attention could be directed toward preparing US for the experience or providing professional development for CTs in regards to working with USs. Given the results of this study, increased communication between the CTs and USs is an opportunity to more fully engage with the process of teacher preparation. This might be accomplished with pre-student teaching seminars or workshops that involve all the members of the process. Establishing specific guidelines that are shared among members might also strengthen this relationship.

\section{Structure for Completion of edTPA}

Although not a regulation generated by the university in the student teaching process, the edTPA requirement has become a necessity during the student teaching process. As indicated in the study, the process was inconsistently incorporated into the student teaching semester, which caused frustration. CTs noted that the emphasis on completion of edTPA distracted STs from the practice of student teaching. In light of this study, further investigation could be made into the role of the CT in the edTPA process. Specific guidelines as to the completion of edTPA could help establish goals for all members. Also, teacher preparation programs might examine the 
ways in which the completion of the edTPA interferes with or enhances the student teaching experience.

\section{CT Desire to Be More Involved}

As indicated in the study, CTs desire a greater level of involvement in the student teaching process. Their expertise and willingness to support the preparation of future teachers is a resource that could be utilized to a greater degree. CTs indicated a willingness to work more extensively with students and university personnel before student teaching which might take the form of classroom visits, presentations, and/or consultations with both instructors and future teachers. According to the results of this study, CTs are willing to make connections before student teaching both in person or through electronic means. Research reveals that when CTs are provided the opportunity, they often develop positive leadership roles within their schools and act as support for university classrooms (Ganser, 1996; Tannehill, 1998). This suggested involvement has potential for positive impacts on students, future teachers, current teachers and university instructors.

\section{Limitations}

Limitations of the study include survey item non-responses. Also, the findings of the study are not generalizable beyond the cooperating teachers working with the student teachers from the Midwestern state university.

Limitations were also present due to the nature of the mixed-methods approach. According to Creswell (2014), some data may be given less weight which might minimize the importance of some information. The sample size was also a limiting factor in that fewer CTs responded than were anticipated. 


\section{Recommendations for Future Studies}

As CTs discussed both in short responses in the survey and in interviews, the advent of edTPA into the process of student teaching has created stress, confusion, and frustration for both the STs and the CTs. Although some recent research has been done to investigate the impact o of edTPA on student teaching (Greenblatt, 2016; Heil \& Berg, 2017), more work should be done. CTs could be useful in observing and analyzing the ways in which edTPA enhances or interrupts the process of successful student teaching.

Further analysis of the data examining the sub groups of CTs in regards to grade level taught, might yield a more in-depth understanding of the data and specific programs. This analysis could enhance understanding of particular components of the teacher preparation programs within the university.

CTs serve as the bridge between the worlds of theoretical pedagogical preparation and practical classroom application. Their role is vital to the future success of teachers in training, and therefore the future success of students in those classrooms (Griffin, et al., 1983; Karmos \&Jacko, 1997; McIntyre \& Byrd, 1998). Unfortunately, CTs’ vital role is overlooked. Future research needs to investigate the multiple ways in which the knowledge and experience of CTs could be better utilized in the preparation of future teachers through an increased connection with university teacher preparation programs. 


\section{REFERENCES}

Allen, D. S., Perl, M., Goodson, L., \& Sprouse, T. (2014). Changing Traditions: Supervision, Co-teaching, and Lessons Learned in a Professional Development School Partnership. Educational Considerations, 42(1), 19-29.

Allen, J. M., Howells, K. \& Radford, R. (2013). A 'Partnership in Teaching Excellence': ways in which one school-university partnership has fostered teacher development. AsiaPacific Journal of Teacher Education, 41 (1), 99-110.

Arnold, P. (2002). Cooperating teachers' professional growth through supervision of student teachers and participation in collegial study group. Teacher Education Quarterly, 29 (2), 123-32.

Ayiro, L. (2012). A Functional Approach to Educational Research Methods and Statistics: Qualitative, Quantitative, and Mixed-Methods Approaches. Edwin Mellen Press, NY.

Baker, P.J. (2011). Three configurations of school-university partnerships: An exploratory study. Planning and Changing, 42 (1/2), 41-62.

Baum, A. C., Powers-Costello, B., VanScoy, I., Miller, E., \& James, U. (2011). We're All in this Together: Collaborative Professional Development with Student Teaching Supervisors. Action in Teacher Education, 33(1), 38-46.

Bradley, A. (1995). Holmes Group urges overhaul of ed. schools. Education Week, 14(19), 1.

Brindley, R., Field, B. E. \& Lessen, E. (2008). What it Means to Be a Professional Development School. National Association for Professional Development Schools.

Brink, B., Laguardia, A., Grisham, D. L., Granby, C., \& Peck, C. A. (2001). Who Needs Student Teachers? Action in Teacher Education, 23(3), 33-45. 
Brinkmann, S., \& Kvale, S. (2015). InterViews: Learning the Craft of Qualitative Research Interviewing. LosAngeles. Sage.

Breault, R. (2014). Power and perspective: the discourse of professional development literature. Asia-Pacific Journal of Teacher Education, 42 (1), 22-35.

Bruemmer, K. H., (2016). Cooperating Teachers' Perspective on Professional Development School Model: Teaching as Learning.

Burton, S. L., \& Greher, G. R. (2007). School-university partnerships: What do we know and why do they matter? Arts Education Policy Review, 109(1), 13-24.

Busby, J. R., \& Mupinga, D. M. (2007). Requirements, Benefits, and Concerns of Technology Education Cooperating Teachers: An Exploratory Study among Nine Midwest Universities. Journal of Technology Studies, 33(2), 79-86.

Castle, S., Fox, R. K., \& Souder, K. O. (2006). Do professional development schools (PDSs) make a difference? A comparative study of PDS and non-PDS teacher candidates. Journal of Teacher Education, 57(1), 65-80.

Chase, K. S., \& Merryfield, M. M. (1998). How Do Secondary Teachers Benefit from PDS Networks? Lessons from a Social Studies and Global Education Learning Community. The Clearing House, (4). 251.

Chesley, G. M., \& Jordan, J. (2012). What's Missing from Teacher Prep. Educational Leadership, 69(8), 41.

Clarke, A. (2001). Characteristics of Co-Operating Teachers. Canadian Journal of Education / Revue canadienne de l'éducation, 26(2). 237-256.

Clarke, A., Triggs, V., \& Nielsen, W. (2014). Cooperating Teacher Participation in Teacher Education: A Review of the Literature. Review of Educational Research, 84(2), 163-202. 
Clinard, L. M., Ariav, T., Minor, L. \& Dwyer, M. (1995). Cooperating Teachers Reflect upon the Impact of Coaching on Their Own Teaching and Professional Life.

Clinard, L. M., \& Ariav, T. (1997). What Mentoring Does for Mentors: A Cross-Cultural Perspective.

Cobb, J. B. (2000). The impact of a professional development school on preservice teacher preparation, inservice teachers' professionalism, and children's achievement: perceptions of inservice teachers. Action in Teacher Education, 22(3), 64-76.

Cornbleth, C., \& Ellsworth, J. (1994). Teachers in Teacher Education: Clinical Faculty Roles and Relationships. American Educational Research Journal, (1). 49.

Creswell, J. W. (2014). Research Design: Qualitative, quantitative, and mixed methods approaches. Los Angeles: Sage.

Creswell, J. W. \& Plano Clark, V. L. (2011) Designing and conducting mixed methods research $\left(2^{\text {nd }}\right.$ ed). Thousand Oak, CA: Sage Publications.

Cucchiara, M. (2010). New goals, familiar challenges: A brief history of university-run schools. Penn GSE Perspectives on Urban Education, 7(1), 96-108.

Cuddapah, J. L., Masci, F. J., Smallwood, J. \& Holland, J. (2008). A Professional development school-sponsored summer program for at-risk secondary students. NASSP Bulletin, 92 (4), 261-275.

Damore, S. J., Kapustka, K. M., \& McDevitt, P. (2011). The urban professional development school network: Assessing the partnership's impact on initial teacher education. The Teacher Educator, 46, 182-207.

Darling-Hammond, L \& McLaughlin, M.W. (2011). Policies that support professional development in an era of reform. Kappan, 92 (6), 81-92. 
Darling-Hammond, L. (2006). Constructing 21st-Century Teacher Education. Journal of Teacher Education, 57(3), 300-314.

Darling-Hammond, L., \& Bransford, J. (Eds) (2005). Preparing teachers for a changing world:

What teachers should learn and be able to do. San Francisco, CA: Jossey-Bass.

Darling-Hammond, L., \& National Commission on Teaching \& America's Future, N. N. (1997). Doing What Matters Most: Investing in Quality Teaching.

Darling-Hammond, (Ed.) (1994). Professional Development Schools: Schools for developing a professional. New York: Teachers College.

DeMonte, J. (2016). Toward Better Teacher Prep. Educational Leadership, 73(8), 66.

Dennis, D. V. (2016). A teacher residency melds classroom theory with clinical practice. Phi Delta Kappan, 97(7), 14.

Dooley, C. M., Dangel, J. R., \& Farran, L. K. (2011). Current Issues in Teacher Education: 20062009. Action in Teacher Education, 33(3), 298-313.

Duncan, A. (2010). Teacher Preparation. Education Digest, 75(5), 13.

Edmondson, S., \& Irby, B. (2008). Ten tips for producing a top qualitative research study. Boston, MA: Pearson Education.

Field, B. E., Blakeney, R., Burton, M., Dunlap, E., Faile, J., Hudson, Z., \& Jackson, M. (2010). The university of South Carolina professional development school network: Twenty years of effective collaboration. School-University Partnerships, 4(2), 41-52.

Foot, K. A. (2014). Cultural-Historical Activity Theory: Exploring a Theory to Inform Practice and Research. Journal Of Human Behavior In The Social Environment, 24(3), 329-347. doi:10.1080/10911359.2013.831011 
Franklin Torrez, C. c., \& Krebs, M. M. (2012). Expert Voices: What Cooperating Teachers and Teacher Candidates Say About Quality Student Teaching Placements and Experiences. Action in Teacher Education (Association of Teacher Educators), 34(5/6), 485-499.

Fraser, J., \& Watson, A.M. (2014). Why clinical experience and mentoring are replacing student teaching on the best campuses. Princeton, NJ: The Woodrow Wilson Fellowship Foundation.

Gallo-Fox, J., \& Scantlebury, K. (2016). Coteaching as professional development for cooperating teachers. Teaching \& Teacher Education, 60191-202.

Ganser, T. (1996). The cooperating teacher role. Teacher Education, 31, 283-291.

Ganser, T., \& Wham, M. A. (1998). Voices of cooperating teachers: professional contributions and personal satisfaction. Teacher Education Quarterly, 25(2), 43-52.

Gareis, C. R., \& Grant, L. W. (2014). The efficacy of training cooperating teachers. Teaching and Teacher Education, 3977-88. doi:10.1016/j.tate.2013.12.007.

Giebelhaus, C. R., \& Bowman, C. (2000). Teaching Mentors: Is It Worth the Effort?.

Grant, G., \& Murray, C.E. (1999). Teaching in America. The slow revolution. Cambridge, MA: Harvard University Press.

Greenblatt, D. p. (2016). The Consequences of edTPA. Educational Leadership, 73(8), 51-54.

Griffin, G. A., \& Barnes, S. P. (1983). Clinical preservice teacher education: final report of a descriptive study. Austin, Tex.: Research and Development Center for Teacher Education, University of Texas at Austin, 1983. 
Grossman, P. L. (1994). In pursuit of a dual agenda: Creating a middle level professional development school. In L. Darling-Hammond (Ed.), Professional development schools: Schools for developing a profession (pp. 50-73). New York: Teachers College Press.

Grossman, P., Smagorinsky, P., \& Valencia, S. (n.d). Appropriating tools for teaching English: A theoretical framework for research on learning to teach. American Journal of Education, 108(1), 1-29.

Heil, L., \& Berg, M. H. (2017). Something Happened on the Way to Completing the edTPA: A Case Study of Teacher Candidates' Perceptions of the edTPA. Contributions To Music Education, 42181-199.

Hoffman, J. V., Wetzel, M. M., Maloch, B., Greeter, E., Taylor, L., DeJulio, S., \& Vlach, S. K. (2015). Review: What can we learn from studying the coaching interactions between cooperating teachers and preservice teachers? A literature review. Teaching and Teacher Education, 5299-112. doi:10.1016/j.tate.2015.09.004.

Holmes Group, I. M. (1995). Tomorrow's Schools of Education: A Report of the Holmes Group. K-12 and Secondary Education (2018). College of Education, Illinois State University. Retrieved from https://education.illinoisstate.edu/secondary/st/.

Kahn, B. (2001). Portrait of success: cooperating teachers and the student teaching experience. Action In Teacher Education (Association Of Teacher Educators), 22(4), 4858.

Karmos, A. H., \& Jacko, C. M. (1977). Role of significant others during the student teaching experience. Journal of Teacher Education, 2851-55. 
Killian, J. E., \& Wilkins, E. A. (2009). Characteristics of Highly Effective Cooperating Teachers: A Study of Their Backgrounds and Preparation. Action in Teacher Education, 30(4), 67-83.

Koerner, M. E. (1992). The cooperating teacher: an ambivalent participant in student teaching. Journal of Teacher Education, 4346-56.

Landt, S. M. (2004). Professional Development of Middle and Secondary Level Educators in the Role of Cooperating Teacher. Action in Teacher Education, 26(1), 74-84.

Levine, A., \& Education Schools, P. (2006). Educating School Teachers.

Libler, R. (2010). Indiana State University professional development school partnership: Systematic, symbiotic, and solution-oriented. School-University Partnerships, 4 (2), 20 30.

Magaya, A., \& Crawley, T. (2011). The Perceptions of School Administrators on the Selection Criteria and Training of Cooperating Teachers; Strategies to Foster Collaboration between Universities Public Schools. International Journal of Educational Leadership Preparation, 6(2).

McCormick, T. M., Eick, C. J., \& Womack, J. S. (2013). Culturally Responsive Teaching: Awareness and Professional Growth through a School-University Collaboration. SchoolUniversity Partnerships, 6(1), 6-14.

McIntyre, D. J., \& Byrd, D. M. (1998). Supervision in teacher education, In G. R. Firth \& E. Pajak (Eds.), Handbook of research on school supervision (pp. 409-427). New York: McMillan.

Melser, N. A. (2004). The Shared Supervision of Student Teachers: Leadership, Listening, and Lessons Learned. Professional Educator, 26(2), 31-37. 
Miller, L., \& Silvernail, D. L. (1994). Wells junior high school: Evolution of a professional development school. In L. Darling-Hammond (Ed.), Professional development schools: Schools for developing a profession (pp. 28-49). New York: Teachers College Press.

Mischler, E. G. (1986). Research interviewing; Context and narrative. Cambridge, MA: Harvard University Press.

Murray, F. B. (1986). Goals for the reform of teacher education: an executive summary of the Holmes Group report. Phi Delta Kappan, 6828-32.

National Council for Accreditation of Teacher, E. (2010). Transforming Teacher Education through Clinical Practice: A National Strategy to Prepare Effective Teachers. Report of the Blue-Ribbon Panel on Clinical Preparation and Partnerships for Improved Student Learning.

Nussbaumer, D. (2012). An overview of cultural historical activity theory (CHAT) use in classroom research 2000 to 2009. Educational Review, 64(1), 37-55.

Onwuegbuzie, A. J. (2012). Introduction: Putting the MIXED back into quantitative and qualitative research in educational research and beyond: Moving toward the radical middle. International Journal Of Multiple Research Approaches, 6(3), 192. doi:10.5172/mra.2012.6.3.192

Parsons, S. A., Parker, A. K., Daoud, N., Bruyning, A. K., Gallagher, M. A., \& Groth, L. A. (2016). Striving to Enact the Professional Development School Philosophy: George Mason University's Elementary Education Program. Teacher Educators' Journal, 9136155. 
Paulson, D., \& Latham, N. (2015). Perceptions of cooperating teachers concerning the student teaching field experience. Normal, Illinois: Illinois State University; Ann Arbor, MI: ProQuest LLC, 2015.

Polizzi, J.A., (2009). Best practices for transformational teacher education: The Full-immersion professional development school alternative. School-University Partnerships, 3 (2), 98 111.

Pushkin, D. (2001). Teacher Training: A reference handbook. Santa Barbara, CA: ABCCLIO.

Ramanathan, H., \& Wilkins-Canter, E. A. (2000). Preparation of cooperating teachers as evaluators in early field experiences. Action in Teacher Education, 22(1), 101-111.

Ridley, D. S., Hurwitz, S., Hackett, M. D., \& Miller, K. K. (2005). Comparing PDS and Campus-based Preservice Teacher Preparation. Journal of Teacher Education, 56(1), 46. doi: $10.1177 / 0022487104272098$

Rosner, S. L., \& Cooper, F. H. (1982). Temple University reading clinic. Journal of Learning Disabilities, 15294-298.

Sandholtz, J. H. \& Dadlez, S. H. (2000). Professional development school trade-offs in teacher preparation and renewal. Teacher Education Quarterly, 27 (1), 7-27.

Sandholtz, J. H., \& Wasserman, K. (2001). Student and cooperating teachers: contrasting experiences in teacher preparation programs. Action in Teacher Education, 23(3), 54-65.

Scheetz, J., Waters, F. H., Smeaton, P., \& Lare, D. (2005). Mentoring in a PDS Program: What's in It for Me?. Kappa Delta Pi Record, 42(1), 33-37.

Schussler, D. L. (2006). The altered role of experience teachers in professional development schools: the present and its possibilities. Issues in Teacher Education, 15 (2), 61-75). 
Shroyer, M. G., Yahnke, S. J., Miller, T., Dunn, C., \& Bridges, N. Y. (2014). The development of the KSU PDS model: 25 Years in the making. Educational Considerations, 42(1), 3.

Tannehill, D. (1989). Student Teaching: A View From the Other Side. Journal Of Teaching In Physical Education, 8(3), 243.

Teitel, L. (2004). Two Decades of Professional School Development in the United States. What Have We Learned? Where Do We Go from Here? Journal of In-Service Education, 4 (3), 401-415.

Theiss, D., \& Grigsby, C. (2010). Measuring the Achievement of Professional Development Schools. School-University Partnerships, 4(1), 29-46.

Tozer, S., Violas, P. C., \& Senese, G. B. (1993). School \& Society: Educational practice as social expression. New York: McGraw-Hill.

Valencia, S., Martin, S., Place, N., \& Grossman, P. (n.d). Complex Interactions in Student Teaching Lost Opportunities for Learning. Journal of Teacher Education, 60(3), 304-322.

Vernon-Dotson, L. J. \& Floyd, L.O. (2012). Building leadership capacity via school partnerships and teacher teams. The Clearing House, 85, 38-49.

Vontz, T.S., Franke, J., Burenheide, B. \& Bietu, L. (2007). Building bridges in Social Studies education: Professional development school partnerships. The Journal of Educational Research, 100 (4), 254-262.

Waddell, J., \& Vartuli, S. (2015). Moving from Traditional Teacher Education to a Field-Based Urban Teacher Education Program: One Program's Story of Reform. Professional Educator, 39(2), 17-39.

Washut Heck, T., \& Bacharach, N. (2015). A better model for student teaching. Educational Leadership, 73(4), 24. 
Weasmer, J., \& Woods, A. M. (2003). Mentoring: Professional Development Through Reflection. Teacher Educator, 39(1), 64-77.

Wilson, S. (2014). Innovation and the Evolving System of US Teacher Preparation. Theory into Practice, 53(3), 183-195.

Wiggins, S. P. (1986). Revolution in the teaching profession: A comparative review of two reform reports. Educational Leadership, 44(2), 56.

Yendol-Silva, D., \& Dana, N. F. (2004). Encountering new spaces: Teachers developing voice within a professional development school. Journal of Teacher Education, 55(2), 128-140.

Zemek, M. D. (2008). The Selection and Preparation of Cooperating Teachers in Music Education. Journal of Music Teacher Education (Online), 17(2), 7-18. 


\section{APPENDIX A: COOPERATING TEACHER SURVEY}

\section{Background Information}

Instructions: Please select only one choice response

1. Gender
○ Male
- Female

2. Grade Level

- Early Elementary (PreK-3)

○ Elementary School (4-5)

○ Middle School (6-8)

$\circ$ High School (9-12)

3. The highest degree I presently hold

$$
\begin{array}{cl}
\circ & \text { Bachelor's } \\
\circ & \text { Master's } \\
\circ & \text { Specialist } \\
\circ & \text { Doctorate }
\end{array}
$$

4. The number of years I have been a classroom teacher:

$$
\begin{array}{ll}
\circ & \text { Less than } 5 \\
\circ & 5-10 \\
\circ & 11-15 \\
\circ & 16+
\end{array}
$$

5. During my years as a professional classroom teacher, I have worked with approximately how many student teachers?

$$
\begin{array}{ll}
\circ & 1-2 \\
\circ & 3-5 \\
\circ & 6+
\end{array}
$$

6. In which program is the current student teacher that you working with?

$$
\begin{array}{ll}
\circ & \text { PDS } \\
\circ & \text { Traditional }
\end{array}
$$

7. Of the student teachers you have worked with, how many were in the PDS program?

How many in traditional program? 


\section{Experience with Student Teaching Process}

Instructions: Please indicate the extent to which you value each of the following as a component of the student teaching process, for this particular student teacher. Please select only one choice response.

\begin{tabular}{|c|c|c|c|c|c|c|}
\hline & & $\begin{array}{c}\text { Extremely } \\
\text { valuable }\end{array}$ & $\begin{array}{c}\text { Somewhat } \\
\text { valuable }\end{array}$ & $\begin{array}{c}\text { Not } \\
\text { Valuable }\end{array}$ & $\begin{array}{c}\text { Somewhat } \\
\text { Detrimental }\end{array}$ & $\begin{array}{c}\text { Extremely } \\
\text { Detrimental }\end{array}$ \\
\hline 8 & $\begin{array}{l}\text { Information } \\
\text { about the student } \\
\text { teacher prior to } \\
\text { the field } \\
\text { experience }\end{array}$ & & & & & \\
\hline 9 & $\begin{array}{l}\text { Detailed } \\
\text { guidelines about } \\
\text { the university } \\
\text { expectations of } \\
\text { the student } \\
\text { teacher }\end{array}$ & & & & & \\
\hline 10 & $\begin{array}{l}\text { Detailed } \\
\text { guidelines about } \\
\text { the university } \\
\text { expectations of } \\
\text { the cooperating } \\
\text { teacher }\end{array}$ & & & & & \\
\hline
\end{tabular}

III. Participation in the Teacher Education Process.

Instructions: Please indicate to what extent you were involved in the teacher education process with this student teacher. Please select only one choice response.

\begin{tabular}{|l|l|l|l|l|}
\hline $\mathbf{1 1}$ & $\begin{array}{l}\text { Communication between the university and } \\
\text { you, the CT, before the student teaching } \\
\text { semester(s) }\end{array}$ & $\begin{array}{c}\text { Extremely } \\
\text { Involved }\end{array}$ & $\begin{array}{c}\text { Somewhat } \\
\text { Involved }\end{array}$ & $\begin{array}{c}\text { Not } \\
\text { Involved }\end{array}$ \\
\hline $\mathbf{1 2}$ & $\begin{array}{l}\text { Specific CT training or preparation to serve as a } \\
\text { CT }\end{array}$ & & & \\
\hline $\mathbf{1 3}$ & $\begin{array}{l}\text { Selection of curriculum for student teachers } \\
\text { prior to the student teaching semester(s) }\end{array}$ & & & \\
\hline $\mathbf{1 4}$ & Instructional methods taught to student teachers & & & \\
\hline
\end{tabular}


15 Consultation between you, the CT, and the student teachers in preparation for student teaching

\section{Program Evaluation}

16. How often do you prefer the university supervisor to observe in your classroom?

○ Weekly

- Every two weeks

- Monthly

- Less than once a month

17. How often would you prefer the university supervisor to check in with you about your student teacher?
$\circ$ Weekly
- Every two weeks
○ Monthly
$\circ$ Less than once a month

18. Do you see the university supervisor as an authority figure or as a colleague?
$\circ$ Authority figure
- Colleague
O Other

19. Do you see the university faculty member as an authority figure or as a colleague?
$\circ$ Authority figure
- Colleague
- Other

20. Would you like to have input on the design of the student teaching field experience?
$\circ$ Yes
○ No
- Maybe

\section{Reflection and Effects on Your Own Classroom Practices}

21. How, if at all, has the cooperating teacher experience impacted or changed your own classroom instruction, curriculum, activities and/or procedures?

23. In what ways might you become more involved in the preparation of the student teacher before they enter student teaching? 
24. How might the student teaching experience be improved for you and/or the student teacher?

25. What benefits, if any, did you gain from acting as a CT?

26. If you have worked with student teachers from both the PDS and traditional program, can you explain any differences that experienced?

27. Anything else you would like to add...

28. Please indicate with your name and summer contact information if you are willing to be interviewed about this topic. The interview will last no more than 1 hour.

\section{Sample Interview Questions}

1. Describe your teaching experience.

2. Tell me about your experiences as a cooperating teacher.

3. How would you describe the level of preparation that student teachers are given before the student teaching experience? Did you notice differences PDS and traditional programs?

4. Please explain how much connection you experience with the university as a cooperating teacher. Did you notice differences between PDS and traditional programs?

5. What are the best parts of working as a cooperating teacher?

6. Can you explain any differences that you notice between student teachers in different student teaching programs?

7. How could your expertise as a cooperating teacher better support the student teaching experience? 


\section{APPENDIX B: RECRUITMENT LETTER}

Recruitment Letter for Cooperating Teachers

Date:

Dear Cooperating Teachers:

I am a graduate student under the direction of Professor Nancy Latham in the School of Teaching and Learning department in the College of Education at Illinois State University. I am conducting a research study to explore the attitudes and experiences of cooperating teachers in the Professional Development School and traditional student teaching models at Illinois State University. The purpose of this study is to investigate the preparation for and participation of the cooperating teacher in the education of future teachers As well, you will be surveyed about any effects the cooperating teacher experience had on your own classroom practices.

Your participation in this study is voluntary. You are not required to participate in this study and may stop your participation at any time by not submitting the survey or responding to the online survey questions. Your responses will be anonymous and any information that might allow someone to identify you will not be disclosed, unless you volunteer the information.

If at any time, prior to, during, or after your participation is completed, you have any questions or concerns regarding this study, please discuss them with Katie Bruemmer, the CoPrincipal Investigator, (xxx)xxx-xxxx or Dr. Nancy Latham, the principal investigator, at (xxx)xxx-Xxxx or the Research Ethics \& Compliance Office at Illinois State University at (xxx) xxx$\operatorname{xxxx}$.

Sincerely,

Katie Bruemmer 